\title{
Interpretation of exercise-induced changes in human skeletal muscle mRNA expression depends on the timing of the post- exercise biopsies
}

\author{
Jujiao Kuang $^{1,2}$, Cian McGinley $^{3}$, Matthew J-C Lee ${ }^{1}$, Nicholas J Saner ${ }^{1,4}$, Andrew Garnham ${ }^{1}$, David J Bishop ${ }^{\text {Corresp. } 1}$ \\ 1 Institute for Health and Sport, Victoria University, Melbourne, Victoria, Australia \\ 2 Australia Institute for Musculoskeletal Sciences, Melbourne, Victoria, Australia \\ 3 Sportscotland Institute of Sport, Stirling, United Kingdom \\ 4 Human Integrative Physiology, Baker Heart and Diabetes Institute, Melbourne, Victoria, Australia \\ Corresponding Author: David J Bishop \\ Email address: David.Bishop@vu.edu.au
}

Background. Exercise elicits a range of adaptive responses in skeletal muscle, which include changes in mRNA expression. To better understand the health benefits of exercise training, it is important to investigate the underlying molecular mechanisms of skeletal muscle adaptation to exercise. However, most studies have assessed the molecular events at only a few time-points within a short time frame post-exercise, and the variations of gene expression kinetics have not been addressed systematically. Methods. We assessed the mRNA expression of 23 gene isoforms implicated in the adaptive response to exercise at 6 time-points $(0,3,9,24,48$, and 72 h post exercise) over a 3-day period following a single session of high-intensity interval exercise. Results. The temporal patterns of target gene expression were highly variable and the expression of mRNA transcripts detected was largely dependent on the timing of muscle sampling. The largest fold change in mRNA expression of each tested target gene was observed between 3 and $72 \mathrm{~h}$ post-exercise.

Discussion and Conclusions. Our findings highlight an important gap in knowledge regarding the molecular response to exercise, where the use of limited time-points within a short period post-exercise has led to an incomplete understanding of the molecular response to exercise. Muscle sampling timing for individual studies needs to be carefully chosen based on existing literature and preliminary analysis of the molecular targets of interest. We propose that a comprehensive time-course analysis on the exercise-induced transcriptional response in humans will significantly benefit the field of exercise molecular biology. 


\section{TITLE}

2 Interpretation of exercise-induced changes in human skeletal muscle mRNA expression

3 depends on the timing of the post-exercise biopsies

5 Jujiao Kuang ${ }^{1,2}$, Cian McGinley ${ }^{3}$, Matthew J-C Lee ${ }^{1}$, Nicholas J Saner ${ }^{1,4}$, Andrew

6 Garnham ${ }^{1}$, and David J Bishop ${ }^{1, *}$.

$8{ }^{1}$ Institute for Health and Sport (iHeS), Victoria University, Melbourne, Victoria, Australia

$9{ }^{2}$ Australia Institute for Musculoskeletal Sciences, Melbourne, Victoria, Australia.

103 Sportscotland Institute of Sport, Airthrey Road, Stirling, Scotland, UK.

$11{ }^{4}$ Human Integrative Physiology, Baker Heart and Diabetes Institute, Melbourne, Victoria,

12 Australia.

13

$15 *$ Corresponding author

16 David J Bishop

17 Institute for Health and Sport (iHeS), Victoria University, Melbourne, Australia

18 E-mail: David.Bishop@vu.edu.au 


\section{ABSTRACT}

22 Background. Exercise elicits a range of adaptive responses in skeletal muscle, which 23 include changes in mRNA expression. To better understand the health benefits of

24 exercise training, it is important to investigate the underlying molecular mechanisms of 25 skeletal muscle adaptation to exercise. However, most studies have assessed the 26 molecular events at only a few time-points within a short time frame post-exercise, and

27 the variations of gene expression kinetics have not been addressed systematically.

28 Methods. We assessed the mRNA expression of 23 gene isoforms implicated in the 29 adaptive response to exercise at 6 time-points $(0,3,9,24,48$, and $72 \mathrm{~h}$ post exercise) 30 over a 3-day period following a single session of high-intensity interval exercise.

31 Results. The temporal patterns of target gene expression were highly variable and the

32 expression of mRNA transcripts detected was largely dependent on the timing of muscle sampling. The largest fold change in mRNA expression of each tested target gene was

34 observed between 3 and $72 \mathrm{~h}$ post-exercise.

35 Discussion and Conclusions. Our findings highlight an important gap in knowledge 36 regarding the molecular response to exercise, where the use of limited time-points within

37 a short period post-exercise has led to an incomplete understanding of the molecular response to exercise. Muscle sampling timing for individual studies needs to be carefully

39 chosen based on existing literature and preliminary analysis of the molecular targets of interest. We propose that a comprehensive time-course analysis on the exercise-induced

41 transcriptional response in humans will significantly benefit the field of exercise molecular 42 biology. 


\section{Introduction}

44 Exercise is a powerful stimulus affecting skeletal muscle, leading to improvements

45 in cardiovascular function, mitochondrial content and function, and whole-body

46 metabolism (Bishop et al. 2019; Cornelissen \& Smart 2013; Granata et al. 2021; Lavie et

47 al. 2015; Philippou et al. 2019). The molecular basis of skeletal muscle adaptations to

48 exercise fundamentally involve modified protein content and enzyme activity, mediated

49 by an array of pre- and post-transcriptional processes, as well as translational and post-

50 translational control (Egan et al. 2016; Egan \& Zierath 2013). From the onset of exercise,

51 muscle contraction can induce disruptions to muscle homeostasis, including mechanical

52 stress, calcium release, ATP turnover, changes to mitochondrial redox state, and reactive

53 oxygen species (ROS) production. These cellular perturbations lead to the activation of

54 signaling molecules that activate a range of transcription factors and coactivators, such

55 as peroxisome proliferator-activated receptor gamma coactivator $1 \alpha$ (PGC-1 $\alpha)$ and p53

56 (Egan \& Zierath 2013). In turn, changes in these and other proteins help to coordinate the

57 transcription of genes associated with mitochondrial biogenesis, fat metabolism, and

58 glucose metabolism (Egan \& Zierath 2013).

59 It has been proposed that training-induced adaptions are due to the cumulative

60 effect of each single exercise session, and that investigating exercise-induced changes

61 in mRNA after a single exercise session can provide important information about the likely

62 adaptations to repeated exercise sessions (i.e., exercise training) (Egan et al. 2013; Perry

63 et al. 2010). Using both quantitative real-time PCR (qPCR) and whole-transcriptome

64 analysis, many studies have provided a better understanding of the transcriptional

65 response to exercise. However, relatively few studies have sampled muscle at multiple 
66 times post exercise or taken biopsies beyond the first 24 hours (Andrade-Souza et al.

67 2020; Catoire et al. 2014; Gidlund et al. 2015; Granata et al. 2020; Hyldahl et al. 2015;

68 Jensen et al. 2015; Lindholm et al. 2014; Liu et al. 2010; Mahoney et al. 2005; McLean

69 et al. 2015; Murton et al. 2014; Neubauer et al. 2014; Ogborn et al. 2015; Pillon et al.

70 2020; Raue et al. 2012; Rowlands et al. 2011; Thalacker-Mercer et al. 2013; Vissing \&

71 Schjerling 2014). A recent study has employed a meta-analysis to profile the skeletal

72 muscle transcriptome using 66 published datasets, providing a useful resource to check

73 the expression of genes of interest in response to a single session of exercise, exercise

74 training, or inactivity (Pillon et al. 2020). However, many of these findings strongly rely on

75 the timing of post-exercise biopsy used in individual studies, and some of these studies

76 provide limited information about the transient nature of exercise-induced changes in

77 gene expression due to few sampling time-points post-exercise. Thus, while there is a

78 general understanding that exercise-induced changes in mRNA expression are time-

79 dependent, more studies are required that extend these analyses to multiple time-points

80 sampled over a prolonged post-exercise period.

81 The absence of a strong justification for the choice of post-exercise biopsy time-

82 point has important implications for our understanding of molecular adaptations to

83 exercise. For example, while Scribbans et al. (Scribbans et al. 2017) reported there was

84 not a systematic upregulation of nuclear and mitochondrial genes $3 \mathrm{~h}$ post-exercise, they

85 also noted that their chosen biopsy time-point might have failed to capture any changes

86 that occurred later in the post-exercise period. Similarly, the lack of increase in p53 mRNA

87 after exercise has been interpreted as evidence that post-translational modification is

88 more important in regulating protein levels of p53 (Saleem \& Hood 2013); but, it is 
89 possible exercise-induced changes in p53 mRNA have been missed by the biopsy time-

90 points chosen to date. Thus, it is clear that the choice of post-exercise biopsy time-point

91 can influence the interpretation of the transcriptional response to exercise (McGinley \&

92 Bishop 2016a; Yang et al. 2005).

93 The purpose of this research was to investigate the temporal expression of

94 commonly assessed, exercise-responsive genes after a single session of endurance-

95 based exercise. We assessed the mRNA expression of key transcription factors

96 associated with exercise-induced mitochondrial biogenesis (PGC-1 $\alpha$ and p53), as well as

97 other genes that have potential roles in mitochondrial and metabolic adaptions to

98 exercise. We hypothesized that different genes would elicit different temporal patterns of

99 expression. The results have helped to highlight the importance of appropriate muscle

100 sample timing and to provide recommendations for designing future studies examining

101 molecular responses to exercise.

102

103 Materials \& Methods

104 Participants

105 As part of a larger project (McGinley \& Bishop 2016a; McGinley \& Bishop 2016b),

10616 recreationally-active men were fully briefed on the procedures, risks, and benefits

107 associated with participating, before providing written informed consent to participate, and

108 for their data to be used in the present study. However, due to the availability of muscle

109 samples, data from only 9 participants were available for the present study [mean (SD);

110 age: 22 (4) y; height: $179.5(7.9) \mathrm{cm}$; mass: $81.4(14.3) \mathrm{kg}$; $\dot{V}_{2 \text { peak: }} 3.9(0.3){\mathrm{L} \cdot \mathrm{min}^{-1}}^{\text {at }}$ 
111 baseline]. All procedures were approved by the Victoria University Human Research

112 Ethics Committee, and the ethics number is HRETH 11/289.

114 Experimental Design

115 Following a familiarisation trial (performed on a separate day; mean (SD), 3 (8)

116 days prior to resting muscle biopsy at baseline), participants completed a graded-

117 incremental exercise test (GXT) to determine baseline levels of peak aerobic power ( $\dot{\mathrm{W}}$

118 peak $)$ and the power at the first lactate threshold $\left(\dot{\mathrm{W}}_{\mathrm{LT}}\right)$. This information was used to

119 individualize the intensity of a single session of high-intensity interval exercise (HIIE). The

120 resting muscle biopsy at baseline was taken on a day before the GXT except for one

121 participant. As part of another study (McGinley \& Bishop 2016b), the participants

122 completed a 4-week high-intensity interval training (HIIT) intervention, training 3 days a

123 week (12 sessions in total). The HIIE session in the present study was the final HIIE

124 session of the HIIT intervention, which was 2 to 4 days after the penultimate HIIE session.

125 To minimise the number of muscle biopsies for each participant, a resting muscle biopsy

126 was taken before starting the 4-week training period (Week 0) and used as the baseline

127 value, as done in previous research (Mahoney et al. 2005; Neubauer et al. 2014).

128 Previously published evidence has reported that the expression of the majority of genes

129 (24686 out of 24838 genes assessed) is not changed at rest before and after 6 weeks of

130 exercise training (Miyamoto-Mikami et al. 2018). Therefore, it is unlikely the fold change

131 in gene expression changes measured in the present study are due to a training effect.

132 Six more biopsies were sampled following the single HIIE session immediately $(0 \mathrm{~h})$, and

133 at $3,9,24,48$, and $72 \mathrm{~h}$ post-exercise (Fig. 1). 
136 Fig. 1. Experimental Design. Abbreviations: BM, body mass; $\mathrm{CHO}$, carbohydrate; PRO,

137 protein; GXT, graded exercise test; HIIE, high-intensity interval exercise; HIIT, high-

138 intensity interval training; $\dot{\mathrm{W}}_{\mathrm{LT}}$, power at the first lactate threshold; and $\dot{\mathrm{W}}_{\text {peak }}$, peak aerobic 139 power.

\section{Graded Exercise Test}

The GXT was conducted pre-training to determine the $\dot{\mathrm{W}}_{\mathrm{LT}}$ and $\dot{\mathrm{W}}_{\text {peak. }}$. All trials were conducted in the morning (06.30-11.30). To determine the $\dot{W}_{\mathrm{LT}}$, a 20-gauge intravenous cannula was inserted into an antecubital vein; venous blood was sampled at rest and at

145 the end of every stage of the GXT, as previously described (McGinley \& Bishop 2016b).

146 The mean coefficient of variation (CV) for duplicate blood lactate measurements was

$1474.6 \%$. The $\dot{W}_{\mathrm{LT}}$ was identified as the power at which venous blood lactate increased $1 \mathrm{mM}$

148 above baseline, and was calculated using Lactate-E software (Newell et al. 2007).

149 The GXT was performed on an electromagnetically-braked cycle ergometer

150 (Excalibur Sport, Lode, Groningen, The Netherlands), using an intermittent protocol

151 consisting of 4-min exercise stages separated by 30-s of rest (Jamnick et al. 2018). The

152 initial load (90 to $150 \mathrm{~W}$ ) was ascertained during the familiarisation GXT, and

153 subsequently increased by $30 \mathrm{~W}$ every $4.5 \mathrm{~min}$, with the aim of minimizing the total

154 number of stages to a maximum of 10 . Participants were required to maintain a cadence

155 of $70 \mathrm{rpm}$, and consistent verbal encouragement was provided during the latter stages.

156 The test was terminated either volitionally by the participant, or by the assessors if the 
157 participant could no longer maintain the required cadence $( \pm 10 \mathrm{rpm})$ despite strong

158 verbal encouragement. $\dot{W}_{\text {peak }}$ was calculated as previously reported (Kuipers et al. 1985):

$159 \quad \dot{\mathrm{W}}_{\text {peak }}=\dot{\mathrm{W}}_{\text {final }}+\left(\frac{t}{240} \times 30\right)$

160 where $\dot{W}_{\text {final }}$ was the power output of the last completed stage and $t$ was the time in

161 seconds of any final incomplete stage.

162

163 High-Intensity Interval Exercise

164 Following an overnight fast, the participants performed a single session of high-

165 intensity interval exercise (HIIE), between 06.30 and 08.00 . The exercise consisted of 7

166 2-min intervals performed on an electromagnetically-braked cycle ergometer (Velotron,

167 Racer-Mate, Seattle, WA), separated by $1 \mathrm{~min}$ of passive recovery (2:1 work:rest). A

168 standardized 5-min steady-state warm-up at $75 \mathrm{~W}$ was completed beforehand. The 169 exercise intensity was set to $\dot{W}_{L T}$ plus $40 \%$ of the difference between $\dot{W}_{L T}$ and $\dot{W}_{\text {peak }}$; i.e.,

$170\left(\dot{\mathrm{W}}_{\mathrm{LT}}\right)+(40 \%)\left(\dot{\mathrm{W}}_{\text {peak }}-\dot{\mathrm{W}}_{\mathrm{LT}}\right)$. Power at the $\mathrm{LT}$ was $65(6) \%$ of $\dot{\mathrm{W}}_{\text {peak }}$, resulting in the HIIE 171 session being undertaken at $79(4) \%$ of $\dot{W}_{\text {peak }}[$ mean (SD)].

173 Dietary Control

174 Participants performed the HIIE session following an overnight fast. Participants

175 were requested to refrain from caffeine consumption on the day of the HIIE, to not ingest

176 any dietary supplements, and to abstain from both alcohol consumption and exercise in

177 the preceding 24-h period. Following the final HIIE session, participants were provided

178 with 2 meals, totaling one-third of their daily energy requirement, based on their predicted 
179 basal metabolism (Harris \& Benedict 1918), and allowing for a 1.4 activity correction factor 180 (Durnin 1996).

181 Following the $0 \mathrm{~h}$ biopsy (i.e., immediately post-HIIE), participants received a 182 standardized breakfast [1416 (230) kJ; mean (SD)], with a target macronutrient content 183 (expressed in g per $\mathrm{kg} \mathrm{BM}$ ) of: $0.6 \mathrm{~g} / \mathrm{kg}$ carbohydrate, $0.2 \mathrm{~g} / \mathrm{kg}$ protein, and $0.1 \mathrm{~g} / \mathrm{kg}$ fat.

184 Following the $3 \mathrm{~h}$ biopsy, participants received a standardized meal [2456 (399) kJ], 185 consisting of: $1.1 \mathrm{~g} / \mathrm{kg}$ carbohydrate, $0.3 \mathrm{~g} / \mathrm{kg}$ protein and $0.1 \mathrm{~g} / \mathrm{kg}$ fat. The total relative 186 macronutrient intake was therefore $64 \%$ carbohydrate, $16 \%$ protein, and $20 \%$ fat.

187 Excluding the standardized meals provided, participants were instructed to ingest only 188 water ad libitum until after the 9-h biopsy. Light activities (e.g., walking) were permitted 189 between the 0 - and 9-h biopsies. All other biopsies (week 0, plus 24, 48, and $72 \mathrm{~h}$ ) were 190 sampled in the morning following an overnight fast, with participants refraining from 191 additional exercise or alcohol consumption until after the final muscle biopsy.

192

193

194

196

197

198

199

200

201

\section{Muscle Sampling}

Muscle biopsies were performed by a qualified medical doctor and taken from the non-dominant leg at rest pre-HIIT (Week 0) and 4 weeks later after the final HIIE session - immediately $(0$ h), $3 \mathrm{~h}, 9 \mathrm{~h}, 24 \mathrm{~h}, 48 \mathrm{~h}$, and $72 \mathrm{~h}$ post-exercise. Muscle samples were taken from the vastus lateralis approximately one third of the distance between knee and hip. Subsequent samples were taken approximately $1 \mathrm{~cm}$ proximal to the previous biopsy site. Local anesthesia (Lidocaine, 1\%) was injected into biopsy site and a 5-mm incision was made once numb, and muscle was sampled using a suction-modified Bergström needle (Bergström 1962). Samples were cleaned of excess blood, fat, and connective 
202 tissue before being immediately snap-frozen in liquid nitrogen, and then stored at $-80{ }^{\circ} \mathrm{C}$

203 for subsequent analyses.

204

205

RNA extraction

qPCR was performed on $n=9$ at all time-points, except for at $72 \mathrm{~h}(n=6)$, using

207 methods established by our group (Kuang et al. 2018). An RNeasy Plus Universal Mini

208 Kit was used to extract total RNA from approximately $20 \mathrm{mg}$ of frozen muscle. Samples

209

were homogenized using a QIAzol lysis reagent and a TissueLyser II (Qiagen, Valencia,

210 USA). The instructions for the kit were modified slightly to increase RNA yield by replacing

211 ethanol with 2-propanol and storing samples at $-20{ }^{\circ} \mathrm{C}$ for $2 \mathrm{~h}$ (Kuang et al. 2018).

212 Purification of RNA samples was performed according to kit instructions using a genomic

213 DNA (gDNA) eliminator solution containing cetrimonium bromide. A BioPhotometer

214 (Eppendorf AG, Hamburg, Germany), was used to determine both the concentration and

215 purity of the RNA samples (based on the $A_{260} / A_{280}$ ratio). RNA integrity of all samples was

216 measured using a Bio-Rad Experion microfluidic gel electrophoresis system (Experion

217 RNA StdSens Analysis kit) and determined from the RNA quality indicator [RQI: 8.8 (0.5)].

218 RNA was stored at $-80^{\circ} \mathrm{C}$ until reverse-transcription was performed.

Reverse transcription

One $\mu \mathrm{g}$ of RNA, in a total reaction volume of $20 \mu \mathrm{L}$, was reverse-transcribed to cDNA using a Thermocycler (Bio-Rad, Hercules, USA) and iScript RT Supermix (Bio-

223 Rad, Hercules, USA) as per the manufacturer's instructions. Priming was performed at

$22425^{\circ} \mathrm{C}$ for $5 \mathrm{~min}$ and reverse transcription for $30 \mathrm{~min}$ at $42^{\circ} \mathrm{C}$. All samples, including $1 \mathrm{RT}$ - 
225 negative control, were run on the same plate. cDNA was stored at $-20{ }^{\circ} \mathrm{C}$ until 226 subsequent analysis.

227

228 qPCR

Relative mRNA expression was measured by qPCR (QuantStudio 7 Flex, Applied

230 Biosystems, Foster City, USA). Primers were designed using Primer-BLAST (Ye et al.

231 2012) and purchased from Sigma-Aldrich (see Table 1 for primer details). All reactions

232 were performed in duplicate on 384-well MicroAmp optical plates (Applied Biosystems,

233 Foster City, USA) using an epMotion M5073 automated pipetting system (Eppendorf AG,

234 Hamburg, Germany). A total reaction volume of $5 \mu \mathrm{L}$ contained $2 \mu \mathrm{L}$ of diluted cDNA

235 template (10- to 160-fold dilution), $2.5 \mu \mathrm{L}$ of mastermix (SsoAdvanced Universal SYBR

236 Green Supermix, Bio-Rad, Hercules, USA), and $0.3 \mu \mathrm{L}$ of primers (5 $\mu \mathrm{M}$ or $15 \mu \mathrm{M})$. All

237 qPCR assays were run for $10 \mathrm{~min}$ at $95^{\circ} \mathrm{C}$, followed by 40 cycles of $15 \mathrm{~s}$ at $95^{\circ} \mathrm{C}$ and 60

$238 \mathrm{~s}$ at $60{ }^{\circ} \mathrm{C}$. The expression of each target gene was normalized to the geometric mean of

239 expression of the 3 most stably expressed reference genes out of 6 potential ones being

240 tested (TBP, PPIA, and B2M) (Vandesompele et al. 2002), and using the $2^{-\Delta \Delta \mathrm{Cq}}$ method

241 (Schmittgen \& Livak 2008).

242

243

[INSERT TABLE 1 HERE]

244 Statistics

RefFinder was utilized for the statistical analysis of reference genes (Xie et al.

246 2012). For change in mRNA expression, statistical analyses were performed on the $2^{-\Delta C q}$

247 data, but the relative expression is reported $\left(2^{-\Delta \Delta C q}\right)$. Geometric means and geometric 
248 standard deviations [geometric mean (GSD)] are reported. A Mann-Whitney U test was

249 used to compare the difference between post-exercise time-points and baseline values

250 as the normality of the distribution calculated with the Shapiro-Wilk test was rejected,

251 which was confirmed by normal probability plot (Q-Q plot). Differentially expressed gene

252 targets post-exercise were first determined using a posteriori information fusion scheme

253 that combines the biological relevance (fold change) and the statistical significance ( $p$

254 value); significance was defined as Xiao value < 0.05 (Deshmukh et al. 2021; Xiao et al.

255 2014). A Benjamini-Hochberg false discovery rate (FDR, Q) of $<5 \%$ was then used to

256 analyze all the $p$ values (GraphPad Prism 8, GraphPad Software, Inc.) (Benjamini \&

257 Hochberg 1995). Lastly, one-way ANOVA with Dunnett test was used to determine the 258 differentially expressed gene targets post-exercise, and significance was defined as 259 adjusted $p$ value $<0.05$ (GraphPad Prism 8, GraphPad Software, Inc.). For modelling of 260 the exercise-induced expression pattern of the target genes, the least-squares Gaussian 261 nonlinear regression analysis (curve fitting) was used to model the peak of mRNA 262 expression using GraphPad Prism 8 (GraphPad Software, Inc.). When examining the 263 relationship between biopsy time associated with peak mRNA expression and the mRNA 264 expression at baseline, basal mRNA expression was calculated from the absolute

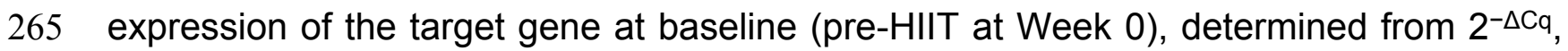
266 multiplied by the dilution of cDNA used in the GPCR reactions. Pearson's correlation

267 coefficient was used to assess the relationship between the basal mRNA expression and 268 the biopsy time with the peak mRNA expression (GraphPad Prism 8, GraphPad Software, 269 Inc.). 


\section{Results}

272 Dynamic gene expression response to exercise in human skeletal muscle

273 The influence of biopsy timing on post-exercise mRNA expression was examined

274 following a single session of HIIE. We measured the mRNA expression of 22 genes (23

275 isoforms) that have been implicated in the adaptive response to exercise (Table 2 and

276 Table S1). Twelve genes showed significant changes (passed at least one of the

277 statistical tests we applied) at the time that elicited the largest fold-change in mRNA

278 expression, and these times varied from $3 \mathrm{~h}$ to $72 \mathrm{~h}$. To illustrate the distinct time-course

279 of mRNA expression in response to exercise, and based on the research interest of our

280 group (i.e., mitochondrial and metabolic adaptive responses to exercise), we chose to

281 focus on 7 genes ( 8 isoforms) that are related to mitochondrial and metabolic adaptations

282 to training, and which elicited peak expression at different times (Fig. 2, presented in the

283 order of the time-point with the largest fold-change in mRNA expression).

[INSERT TABLE 2 HERE]

[INSERT FIGURE 2 HERE]

289 Fig. 2. Relative fold changes compared to baseline for the mRNA expression of PGC-1a 290 (a), PGC-1a4 (b), PPARa (c), PDK4 (d), NRF1 (e), CD36 (f), p53 (g), and GLUT4 (h),

291 following a single session of HIIE. Muscle biopsies were obtained at rest (baseline) before 2924 weeks of High-Intensity Interval Training (HIIT), immediately after the final session of 
293 HIIE $(0 \mathrm{~h})$, and $3,9,24,48$, and $72 \mathrm{~h}$ after exercise $(\mathrm{n}=9$ participants for all times, except

294 for $72 \mathrm{~h}$ where $\mathrm{n}=6$ ). Symbols (open circles and squares) of the same color indicate

295 mRNA data from 1 participant; the geometric mean (horizontal bars) \pm the $95 \%$

296 confidence interval $(\mathrm{Cl})$ are plotted for each graph. The squares indicate the data point

297 with highest or lowest mRNA expression for each participant. A dotted line was used to

298 indicate $\mathrm{Y}=1 .{ }^{*}$ Significantly different from baseline, determined by a posteriori

299 information fusion scheme and a Benjamini-Hochberg false discovery rate (FDR) of $<5 \%$.

300 \# Significantly different from baseline, determined by a posteriori information fusion

301 scheme only.

302

303 The mean of the mRNA expression of $P G C-1 \alpha$, exercise-induced isoform

$304 P G C-1 \alpha 4$, and PPAR $\alpha$, increased significantly $3 \mathrm{~h}$ post-exercise and was not significantly

305 different from baseline at $9 \mathrm{~h}$ post-exercise (Fig. 2a to 2c). All 9 participants had the

306 highest expression level of PGC-1a, PGC-1a4, and PPAR $\alpha$ mRNA at $3 \mathrm{~h}$ post-exercise

307 (except 1 participant who had the highest $P G C-1 a 4$ mRNA expression at $0 \mathrm{~h}$ ). A similar

308 result was observed for CPT1A; the highest mRNA expression for the group mean, and

309 the highest value for 7 out of 9 individuals, occurred $3 \mathrm{~h}$ post-exercise with values not

310 significantly different from baseline at $9 \mathrm{~h}$ post-exercise (Table 2, individual data shown

311 in Table S2 and S3).

312 The highest mean for the mRNA expression of PDK4 occurred at $9 \mathrm{~h}$ post-exercise

313 (Fig. 2d). HSP1A1, SDHB, COX4-1, NDUFB3, VEGFA, and PGC-1 $\beta$ showed the

314 greatest, but not significant, induction of mRNA expression at $9 \mathrm{~h}$ post-exercise (Table 315 S1). 
The mean mRNA expression of NRF1 was highest at $24 \mathrm{~h}$ post-exercise (Fig. 2e),

317 and the mean mRNA expression of CD36 had the greatest decrease at $24 \mathrm{~h}$ post-exercise

318 (Fig. 2f). Most participants showed the highest or lowest mRNA expression between 3

319 and 24 h post-exercise (7 out of 9 participants for NRF1, and 8 out of 9 participants for

$320 C D 36$, respectively). TFEB, UCP3, CS, TAFM, UQCRC2, and PPAR $/ \delta$ also showed the

321 highest or lowest expression level at $24 \mathrm{~h}$; however, only changes in TFEB and UCP3

322 reached significance (Table 2 and Table S1).

323 The mean p53 mRNA expression was significantly greater than baseline from 9 to

$32472 \mathrm{~h}$ post-exercise, with the highest expression $48 \mathrm{~h}$ post-exercise (Fig. $2 \mathrm{~g}$ ). PPARY

325 showed significant induction of mRNA expression at $48 \mathrm{~h}$ post-exercise (Table 2).

326 Participants showed a small decrease of GLUT4 mRNA expression compared to

327 baseline, and the lowest mRNA expression was found at $72 \mathrm{~h}$ after exercise (Fig. $2 \mathrm{~h}$ ).

328 The decrease of the mean mRNA expression was significant at all time-points except $3 \mathrm{~h}$

329 and $9 \mathrm{~h}$ post-exercise. MFN2 had the highest mRNA expression at $72 \mathrm{~h}$ post-exercise;

330 however, this change was not significant (Table S1).

331

332 Modeling the gene expression response to exercise

We used a least-squares Gaussian nonlinear regression analysis to model the

334 exercise-induced expression pattern of the target genes (Fig. 3). Using the mRNA expression from 0 to $48 \mathrm{~h}$ after exercise (the time span in which most of the transcriptional

336 responses were observed), the best curve fit was generated based on the group mean

337 mRNA expression. The predicted peak mRNA expression time was identified based on 338 the regression curve. The modelled peak mRNA expression time ranged from $4.6 \mathrm{~h}$ 
339 (PPAR $\alpha$ ) to $34.8 \mathrm{~h}$ (p53) post-exercise (Fig. 4). CD36, GLUT4, TFEB, and PPARY were

340 not used in this analysis as there was no peak in gene expression detected using curve

341 fitting. We then established the time window within which each target gene's expression

342 level was within $90 \%$ of its most changed mRNA expression. The genes that responded

343 earlier tended to have a shorter time window within $10 \%$ of most changed mRNA

344 expression, whereas the genes that responded later had a larger time window.

\section{[INSERT FIGURE 3 HERE]}

348 Fig. 3. Curve fitting applied to mRNA changes following a single session of high-intensity 349 interval exercise (HIIE). Least-squares Gaussian nonlinear regression analysis (dash 350 lines) has been applied to gene expression data for PGC-1a (a), PGC-1a4 (b), PPARa

351 (c), PDK4 (d), NRF1 (e), CD36 (f), p53 (g), and GLUT4 (h) at 5 time-points (0, 3, 9, 24 and $48 \mathrm{~h}$ following a single session of HIIE) in 9 participants. The geometric mean of gene expression is indicated by black dots, error bars are geometric standard deviations.

\section{[INSERT FIGURE 4 HERE]}

357 Fig. 4. Modelled time of mRNA expression peak following a single session of high358 intensity interval exercise in relation to biopsy timing in 9 participants. The peak expression time (black dots) and the time window for the top 10\% of mRNA expression

360 (vertical lines) were calculated based on regression analysis and is shown for the 7 genes

361 (8 isoforms) for which a peak of gene expression was detected using curve fitting. 
362 Gene expression timing plotted against basal expression level

363 To determine if the diverse gene expression timing after exercise depends on its

364 basal expression level in skeletal muscle, we then plotted basal mRNA expression levels

365 of the 12 gene targets with significant changes against the biopsy time that elicited the

366 peak mRNA expression after exercise. There was no clear relationship between the

367 mRNA expression level at baseline and the biopsy time-point that corresponded with the

368 largest change in gene expression ( $r=-0.042, P=0.898$, Fig. 5).

369

370

\section{[INSERT FIGURE 5 HERE]}

371

372 Fig. 5. The biopsy time associated with peak mRNA expression in 9 participants plotted 373 against the mRNA expression at baseline for 12 gene isoforms. Pearson's correlation 374 coefficient and $p$ value are shown.

375

376 Discussion

The present study examined changes in the mRNA expression of 23 targets at 6

378 time-points, over a period of $72 \mathrm{~h}$, after a single session of high-intensity interval exercise

379 in 9 healthy participants. We found that changes in gene expression were highly 380 dependent on the biopsy timing, and that the greatest changes in mRNA expression were 381 observed between 3 and $72 \mathrm{~h}$ post-exercise. For many genes, there was considerable

382 individual variability for the time at which the most changed mRNA expression was 383 observed, especially for genes that responded at later time-points. 
We observed distinct temporal patterns of gene expression after exercise, which

385 is consistent with previous research. For example, Yang et al. (Yang et al. 2005) examined the mRNA expression of several genes at 7 time-points from 0 to $24 \mathrm{~h}$ after resistance exercise and found that the timing of mRNA induction of their target genes was also variable. They reported that the mRNA expression of muscle regulatory factor 4 (MRF4) and PDK4 reached their highest levels $4 \mathrm{~h}$ post-exercise, whereas myogenin and hexokinase II $(H K I I)$ reached their highest levels $8 \mathrm{~h}$ post-exercise. Another study assessed exercise-induced gene expression at 3 h, 48 h, and $96 \mathrm{~h}$ after an endurance exercise session comprised of 60 min of intense cycling followed immediately by 60 min of intense running (Neubauer et al. 2014). Their results showed that the highest mRNA expression of some targets, such as hemeoxygenase 1 (HMOX1) and integrin beta 2 (ITGB2), occurred $96 \mathrm{~h}$ post-exercise, whereas other targets, such as $P G C-1 \alpha$, had the highest observed mRNA expression at $3 \mathrm{~h}$ post-exercise. These findings clearly highlight how biopsy timing has the potential to influence the interpretation of exercise-induced transcriptional responses. For example, if we had only taken a biopsy $3 \mathrm{~h}$ post-exercise in the current study (which is common practice), we would have incorrectly concluded that genes such as PDK4, NRF1, CD36, and $p 53$ were not affected by our exercise 401 stimulus.

The literature is consistent with our observation that the average mRNA expression of $P G C-1 \alpha$, as well as the exercise-induced isoform $P G C-1 \alpha 4$, increased significantly $3 \mathrm{~h}$ after a single session of HIIE, and then returned to baseline at $9 \mathrm{~h}$ post-exercise. Previous studies have reported that PGC-1 $\alpha$ mRNA increases 2- to 15-fold, 2 to $5 \mathrm{~h}$ after a single session of exercise in humans (summarised in (Granata et al. 2018)). In another review 
407 article, Islam et al. (Islam et al. 2018) compared 19 human studies with diverse exercise

408 protocols and muscle sampling time-points; all studies reported an increase in PGC-1a

409 mRNA expression, except 1 study that performed a biopsy $24 \mathrm{~h}$ post-exercise. A recent

410 meta-analysis, which integrated 66 published dataset using gene ontology and pathway

411 analyses, confirmed that PGC-1a mRNA increases 2.3-fold after a single session of

412 aerobic exercise (Pillon et al. 2020).

413 When we investigated downstream targets of PGC-1 $\alpha$ protein (a transcriptional

414 coactivator (Handschin \& Spiegelman 2006)), we observed that the mRNA expression of

415 PDK4 was significantly higher at $9 \mathrm{~h}$ post-exercise, and the mRNA expression of NRF1

416 mRNA reached its highest level at $24 \mathrm{~h}$ post-exercise. Our results suggest the

417 downstream targets of the master regulator PGC-1 $\alpha$ are induced by a single session of

418 exercise but follow a delayed time-course. Our findings support the proposal by Scribbans

419 and colleagues that the absence of a systematic upregulation of PGC-1a targets could

420 be because changes in some targets were not captured by their chosen biopsy time ( $3 \mathrm{~h}$

421 post-exercise) (Scribbans et al. 2017). However, we observed no significant changes in

422 mRNA expression of some downstream targets of PGC-1 $\alpha$, such as TFAM, COX4-1, and

423 CS. A review article by Islam et al. (Islam et al. 2018) reported contrasting observations

424 when the expression of those genes targets were examined. For 18 studies that observed

425 an increase in PGC-1 $\alpha$ mRNA expression, 12 studies reported an increased expression

426 of mitochondrial transcriptional factor TFAM with at least 1 exercise protocol or time-point

427 (biopsy times ranging from 0 to $24 \mathrm{~h}$, but mostly within $6 \mathrm{~h}$ post-exercise), and 6 studies

428 reported no change (biopsy times ranging from 0 to $6 \mathrm{~h}$ post-exercise). Islam et al. also

429 reported different results for gene expression of COXIV (induced at $3 \mathrm{~h}$ post-exercise or 
430 no change), and CS (induced at $5 \mathrm{~h}$ post-exercise or no change) from separate studies.

431 There is no clear explanation for the contrasting results; however, the authors suggested

432 this lack of coordination could be due to the divergent temporal expression pattern of

433 different genes and recommended a more thorough investigation of the exercise-induced

434 gene expression time-course in future human studies. The lack of significant changes in

435 some PGC-1a downstream targets from this present study could be due to the study

436 being underpowered to detect a clear change.

437 The tumor suppressor p53 is another important regulator of mitochondrial

438 biogenesis and known to be induced by exercise (Granata et al. 2016; Saleem et al.

439 2011). We report a 2- to 2.5 -fold increase of p53 mRNA from 24 to $48 \mathrm{~h}$ post-exercise,

440 with the highest mRNA expression (2.3-fold) observed at $48 \mathrm{~h}$ post-exercise. Unlike $P G C$ -

$4411 \alpha$, the exercise-induced changes in p53 mRNA expression are not consistent across the

442 literature. For example, Edgett et al. reported a small induction of p53 mRNA expression

443 (less than 1.5-fold) after high-intensity interval cycling of varying intensities (73 to $133 \% \mathrm{~W}$

444 peak) (Edgett et al. 2013). Conversely, Hammond et al. reported a 2- to 3-fold increase in

445 p53 mRNA expression between 4.5 and $19.5 \mathrm{~h}$ after a high-intensity interval running

446 session ( $8 \times 5 \mathrm{~min}$ at $85 \% \dot{\mathrm{VO}}_{2 \text { peak }}$ ); their participants also performed a 60 -min steady-

447 state run $\left(70 \% \dot{V}^{2} O_{2 e a k}\right)$ between the running session and post-exercise biopsies

448 (Hammond et al. 2016). Differences in the prescribed exercise intensities and volumes

449 may therefore contribute to the inconsistent findings between studies. However, in two of

450 our previous human studies, we observed no significant changes in p53 mRNA

451 expression immediately and $3 \mathrm{~h}$ after either moderate-intensity continuous $\left(63 \% \mathrm{~W}_{\text {peak }}\right)$

452 or "all-out" sprint interval cycling sessions (Granata et al. 2017), nor after high-intensity 
453 interval cycling $\left(\sim 79 \% \dot{\mathrm{W}}_{\text {peak }}\right)$ whether preceded by a prior exercise session or not

454 (Andrade-Souza et al. 2020).

455 The half-life of mRNA is important for the kinetics of gene expression, as mRNA 456 expression is determined by the rates of both RNA synthesis and degradation. It has been 457 reported that many transcription factors and regulatory proteins have short half-lives 458 (Uhlitz et al. 2017; Yang et al. 2003). In a study that analyzed mRNA half-lives in human 459 B-cells, the authors reported that genes involved in transcription factor activity, 460 transcription, and transcription factor binding, are short-lived, with median half-lives 461 ranging between 3.6 to $4.3 \mathrm{~h}$, whereas genes involved in glucose and fatty acid metabolic 462 process have longer median half-lives of 7.5 to $10.1 \mathrm{~h}$ (Friedel et al. 2009). This matches 463 our observation that transcription factors and coactivators, such as PGC-1 $\alpha$ and PPARa, 464 are fast-responding genes following exercise. In contrast, genes with functions in glucose 465 metabolism (PDK4) and fatty-acid metabolism (CD-36 and UCP3) took longer to be 466 induced after our exercise stimulus. It has also been suggested that the kinetics of mRNA

467 induction are influenced by basal expression levels, in addition to the activation of 468 transcription and mRNA turnover (Booth \& Neufer 2012). However, our results indicate 469 that the diverse expression timing of different genes after a single session of exercise 470 stimuli depends more on the function/role of the target gene in the process of the 471 adaptative response than its basal expression level in skeletal muscle (i.e., time to peak 472 expression did not seem to be related to mRNA expression level at baseline; Fig. 5).

473 Due to limitations regarding the number of muscle biopsies that can be obtained

474 in a single experiment, it was not possible to determine the precise peak expression time 475 of each target gene in the present study. Thus, we decided to model the peak expression 
476 timing of target genes based on the observed mRNA changes in all participants. Previous

477 time-course studies in human subjects (Mathai et al. 2008; McGinley \& Bishop 2016a;

478 Pilegaard et al. 2003; Yang et al. 2005), as well as our present experiment, observed that

479 the majority of the exercise responsive genes followed a similar pattern: an initial

480 upregulation to an observed peak level followed by a return to baseline levels. Based on

481 these observations, we chose least-squares Gaussian nonlinear regression modelling to

482 analyze the expression pattern using the gene expression data from 0 to $48 \mathrm{~h}$ post-

483 exercise. The reasons for only including the time-points within the first $48 \mathrm{~h}$ post-exercise

484 include: 1) the largest changes in mRNA expression for the majority of genes occurred

485 within the first 2 days after exercise; 2 ) the low number of participants available for the

486 72-h post-exercise biopsy. Based on this model, we mapped out the time window eliciting

487 the highest or lowest $10 \%$ of gene expression after exercise (Fig. 4). One limitation of our

488 modelling method, however, is that this parametric regression is strongly based on the

489 assumption that the genes followed the modelled pattern. Furthermore, the large

490 individual variation between participants, the relatively low number of participants, and

491 the limited number of muscle biopsies taken, undoubtedly affected the accuracy of our

492 regression analysis. An even more comprehensive study, with more participants, more

493 biopsy time-points, and a greater number of genes (assessed with RNAseq) is necessary

494 to construct a more accurate picture of the kinetics of mRNA expression in response to 495 exercise.

496 To standardize the exercise dose, we prescribed the same relative intensity and

497 duration of HIIE for all participants. Nevertheless, we still observed large variability in both

498 the timing and the magnitude of the transcriptional response between individuals. This is 
499 consistent with previous research showing that not all individuals respond the same way

500 to a standardized exercise dose (Bouchard \& Rankinen 2001; Jamnick et al. 2020; Ross

501 et al. 2015). This individual response could be due to genetic background, non-genetic

502 biological and behavioral factors, circadian fluctuations, and technical or biological

503 variability associated with the sampling of human skeletal muscle and the analysis of

504 exercise-induced mRNA (Islam et al. 2019; Ross et al. 2019). We add that the timing of

505 the observed peak for exercise-induced expression of different genes also differed

506 between individuals. This further highlights that it is probably not possible to choose a

507 single post-exercise biopsy time-point that will capture changes in the expression of 508 specific genes for all individuals.

509 In the present study, participants underwent 4-weeks of HIIT before the single 510 session of HIIE and post-exercise muscle sampling. This prior training period may have

511 influenced our interpretation of results when compared to the pre-training baseline values.

512 However, Miyamoto-Mikami et al. (Miyamoto-Mikami et al. 2018) reported that of 24838

513 genes assessed, there were only 152 differentially expressed genes after 6 weeks of

514 exercise training: 79 genes significantly up-regulated (fold change between 1.2 to 2) and

51573 genes significantly down-regulated (fold change between 0.5 to 0.8 ). Only 1 of our

516 target genes (PGC-1 $\alpha)$ overlapped with their 152 differently expressed genes. This

517 suggests the fold change in gene expression changes detected in this present study are

518 likely to be representative of the adaptive response to the single session of exercise,

519 rather than the training. Another study has also shown there was no difference in the

520 mRNA expression of PGC-1 $\alpha, P G C-1 \beta, T F A M, C S$ and COXIV after 10 days of intensive

521 cycling training (Stepto et al. 2012). It is still possible that the magnitude or lack of fold 
522 change in the expression of some gene targets could be due to the training period in our

523 study. For example, it has been shown that training was able to increase GLUT4 mRNA

524 expression (Stuart et al. 2010), which could explain the lack of induction of GLUT4 mRNA

525 expression following exercise that we observed in trained individuals. Despite this

526 limitation in our study design, it is important to note that our primary interest was to

527 investigate temporal changes in gene expression and not the fold changes from baseline

528 or the expression of every individual gene target.

529 Another limitation of the present study is the possible influence on mRNA 530 expression from non-exercise factors, such as repeated muscle biopsies, the post-

531 exercise nutrition control, and circadian rhythms. It has previously been demonstrated

532 that the expression of some gene targets was induced by stimuli other than exercise,

533 such as feeding and the stress from repeated muscle biopsies. However, this observation

534 could be due to the high-glycemic meal that was provided to the participants after the first

535 biopsy (Vissing et al. 2005). Other studies have clearly demonstrated that prior muscle

536 biopsies had no effect on mRNA expression of specific genes, including PGC-1a, PDK4,

537 and GLUT4 (Lundby et al. 2005; Psilander et al. 2003). Furthermore, other studies have

538 shown that some mRNA transcripts follow a circadian pattern of expression (Kemler et al.

539 2020; Saner et al. 2020); however, considering that participants all performed the

540 exercise session and ate meals at the same time of the day this is unlikely to have

541 confounded the results of this study.

542 Another critical factor to interpret the gene expression data obtained from human

543 exercise studies is the use of the most appropriate statistical analyses. The common

544 issues with human exercise studies include relatively small sample sizes, large individual 
545 variability, and not correctly controlling for multiple comparisons. Future research

546 investigating a time-course analysis of exercise-induced transcriptional responses in

547 humans should employ larger sample sizes and ensure that statistical analyses

548 adequately control for multiple comparisons.

549 It is important to note that our results are likely to be specific to the participants

550 recruited and the exercise employed. It has previously been reported that both training

551 and fitness level can affect exercise-induced gene expression (Popov et al. 2018; Popov

552 et al. 2017). Thus, the time courses we have reported cannot be assumed for other

553 populations (e.g., sedentary and untrained participants, or elite athletes). Many studies

554 have also reported intensity-dependent changes in gene expression (Edgett et al. 2013;

555 Egan et al. 2010; Sriwijitkamol et al. 2007). It remains to be determined if the time courses

556 we have reported are also influenced by exercise intensity.

557 It is also worth mentioning that adaptive responses to exercise training consist of

558 changes in steady-state protein abundance, along with subsequent functional

559 adjustments (e.g., changes in enzyme activities) (Perry et al. 2010). These adaptations

560 are collectively determined by rates of mRNA transcription, mRNA degradation,

561 translation, and protein degradation. Nonetheless, it has been reported by Li et al. that

562 variance in mRNA expression explains more than $80 \%$ of the variance in protein levels

563 ( $\mathrm{Li}$ et al. 2014). This suggests that better characterizing transcriptional responses to

564 exercise does contribute to understanding the adaptive response to exercise training. 


\section{Conclusions}

In summary, this study monitored the temporal expression of mRNA with multiple

568 time-points over $72 \mathrm{~h}$ after a single exercise session. We observed distinct temporal

569 patterns for the expression of different genes, with the time for the highest observed gene

570 expression varying from 3 to $48 \mathrm{~h}$ post-exercise. These findings highlight an important

571 limitation when studying the molecular responses to exercise, where few (2 to 3) biopsies

572 are commonly sampled in a short time frame (i.e., less than $24 \mathrm{~h}$ post exercise) to

573 examine transcriptional responses to exercise. These results further emphasize the

574 importance of carefully planning biopsy time-points to best capture, and interpret,

575 exercise-induced changes in genes of interest.

576

577 Acknowledgements

578 We are very grateful to the participants for their time and effort. We also thank Dr Mitch

579 Anderson for performing some of the muscle biopsies.

580

581 References

582 Andrade-Souza VA, Ghiarone T, Sansonio A, Santos Silva KA, Tomazini F, Arcoverde L, Fyfe

583 J, Perri E, Saner N, Kuang J, Bertuzzi R, Leandro CG, Bishop DJ, and Lima-Silva AE. 2020.

584 Exercise twice-a-day potentiates markers of mitochondrial biogenesis in men. Faseb j 34:1602-

585 1619. 10.1096/fj.201901207RR

586 Benjamini Y, and Hochberg Y. 1995. Controlling the false discovery rate: a practical and

587 powerful approach to multiple testing. Journal of the Royal statistical society: series B

588 (Methodological) 57:289-300. 10.1111/j.2517-6161.1995.tb02031.x 
589 Bergström J. 1962. Muscle electrolytes in man determined by neutron activation analysis on 590 needle biopsy specimens. Scandinavian journal of clinical and laboratory investigation 14:1591110.

592 Bishop DJ, Botella J, Genders AJ, Lee MJ, Saner NJ, Kuang J, Yan X, and Granata C. 2019. 593 High-Intensity Exercise and Mitochondrial Biogenesis: Current Controversies and Future 594 Research Directions. Physiology (Bethesda) 34:56-70. 10.1152/physiol.00038.2018

595 Booth F, and Neufer P. 2012. Exercise genomics and proteomics. In: Farrrell P, Joyner M, and 596 Caiozzo V, eds. ACSM's Advanced Exercise Physiology. Baltimore: Lippincott Williams \& 597 Wilkins, 669-698.

598 Bouchard C, and Rankinen T. 2001. Individual differences in response to regular physical 599 activity. Med Sci Sports Exerc 33:S446-451; discussion S452-443. 10.1097/00005768$600 \quad 200106001-00013$.

601 Catoire M, Alex S, Paraskevopulos N, Mattijssen F, Evers-van Gogh I, Schaart G, Jeppesen J, 602 Kneppers A, Mensink M, Voshol PJ, Olivecrona G, Tan NS, Hesselink MK, Berbee JF, Rensen 603 PC, Kalkhoven E, Schrauwen P, and Kersten S. 2014. Fatty acid-inducible ANGPTL4 governs 604 lipid metabolic response to exercise. Proc Natl Acad Sci U S A 111:E1043-1052. 605 10.1073/pnas.1400889111

606 Cornelissen VA, and Smart NA. 2013. Exercise training for blood pressure: a systematic review 607 and meta-analysis. J Am Heart Assoc 2:e004473. 10.1161/JAHA.112.004473

608 Deshmukh AS, Steenberg DE, Hostrup M, Birk JB, Larsen JK, Santos A, Kjobsted R, Hingst JR, 609 Scheele CC, Murgia M, Kiens B, Richter EA, Mann M, and Wojtaszewski JFP. 2021. Deep 610 muscle-proteomic analysis of freeze-dried human muscle biopsies reveals fiber type-specific 611 adaptations to exercise training. Nat Commun 12:304. 10.1038/s41467-020-20556-8

612 Durnin JV. 1996. Energy requirements: general principles. Eur J Clin Nutr 50 Suppl 1:S2-9; 613 discussion 9-10.

614 Edgett BA, Foster WS, Hankinson PB, Simpson CA, Little JP, Graham RB, and Gurd BJ. 2013. 615 Dissociation of increases in PGC-1alpha and its regulators from exercise intensity and muscle 616 activation following acute exercise. PLoS One 8:e71623. 10.1371/journal.pone.0071623 
617 Egan B, Carson BP, Garcia-Roves PM, Chibalin AV, Sarsfield FM, Barron N, McCaffrey N, 618 Moyna NM, Zierath JR, and O'Gorman DJ. 2010. Exercise intensity-dependent regulation of 619 peroxisome proliferator-activated receptor coactivator-1 mRNA abundance is associated with 620 differential activation of upstream signalling kinases in human skeletal muscle. J Physiol 621 588:1779-1790. 10.1113/jphysiol.2010.188011

622 Egan B, Hawley JA, and Zierath JR. 2016. SnapShot: Exercise Metabolism. Cell Metab 24:342623342 e341. 10.1016/j.cmet.2016.07.013

624 Egan B, O'Connor PL, Zierath JR, and O'Gorman DJ. 2013. Time course analysis reveals gene625 specific transcript and protein kinetics of adaptation to short-term aerobic exercise training in 626 human skeletal muscle. PLoS One 8:e74098. 10.1371/journal.pone.0074098

627 Egan B, and Zierath JR. 2013. Exercise metabolism and the molecular regulation of skeletal 628 muscle adaptation. Cell Metab 17:162-184. 10.1016/j.cmet.2012.12.012

629 Friedel CC, Dolken L, Ruzsics Z, Koszinowski UH, and Zimmer R. 2009. Conserved principles 630 of mammalian transcriptional regulation revealed by RNA half-life. Nucleic Acids Res 37:e115. 631 10.1093/nar/gkp542

632 Gidlund EK, Ydfors M, Appel S, Rundqvist H, Sundberg CJ, and Norrbom J. 2015. Rapidly 633 elevated levels of PGC-1alpha-b protein in human skeletal muscle after exercise: exploring 634 regulatory factors in a randomized controlled trial. J Appl Physiol (1985) 119:374-384.

635 10.1152/japplphysiol.01000.2014

636 Granata C, Caruana NJ, Botella J, Jamnick NA, Huynh K, Kuang J, Janssen HA, Reljic B, 637 Mellett NA, Laskowski A, Stait TL, Frazier AE, Coughlan MT, Meikle PJ, Thorburn DR, Stroud 638 DA, and Bishop DJ. 2021. High-intensity training induces non-stoichiometric changes in the 639 mitochondrial proteome of human skeletal muscle without reorganisation of respiratory chain 640 content. Nature Communications 12:7056. 10.1038/s41467-021-27153-3

641 Granata C, Jamnick NA, and Bishop DJ. 2018. Principles of Exercise Prescription, and How 642 They Influence Exercise-Induced Changes of Transcription Factors and Other Regulators of 643 Mitochondrial Biogenesis. Sports Med 48:1541-1559. 10.1007/s40279-018-0894-4 
644 Granata C, Oliveira RS, Little JP, Renner K, and Bishop DJ. 2016. Training intensity modulates 645 changes in PGC-1 $\alpha$ and p53 protein content and mitochondrial respiration, but not markers of 646 mitochondrial content in human skeletal muscle. The FASEB Journal 30:959-970.

647 Granata C, Oliveira RS, Little JP, Renner K, and Bishop DJ. 2017. Sprint-interval but not 648 continuous exercise increases PGC-1alpha protein content and p53 phosphorylation in nuclear 649 fractions of human skeletal muscle. Sci Rep 7:44227. 10.1038/srep44227

650 Granata C, Oliveira RSF, Little JP, and Bishop DJ. 2020. Forty high-intensity interval training 651 sessions blunt exercise-induced changes in the nuclear protein content of PGC-1alpha and p53 in 652 human skeletal muscle. Am J Physiol Endocrinol Metab 318:E224-E236.

653 10.1152/ajpendo.00233.2019

654 Hammond KM, Impey SG, Currell K, Mitchell N, Shepherd SO, Jeromson S, Hawley JA, Close 655 GL, Hamilton LD, Sharples AP, and Morton JP. 2016. Postexercise High-Fat Feeding 656 Suppresses p70S6K1 Activity in Human Skeletal Muscle. Med Sci Sports Exerc 48:2108-2117. 657 10.1249/MSS.0000000000001009

658 Handschin C, and Spiegelman BM. 2006. Peroxisome proliferator-activated receptor gamma 659 coactivator 1 coactivators, energy homeostasis, and metabolism. Endocr Rev 27:728-735. $660 \quad 10.1210 /$ er.2006-0037

661 Harris JA, and Benedict FG. 1918. A Biometric Study of Human Basal Metabolism. Proc Natl 662 Acad Sci U S A 4:370-373. 10.1073/pnas.4.12.370

663 Hyldahl RD, Nelson B, Xin L, Welling T, Groscost L, Hubal MJ, Chipkin S, Clarkson PM, and 664 Parcell AC. 2015. Extracellular matrix remodeling and its contribution to protective adaptation 665 following lengthening contractions in human muscle. FASEB J 29:2894-2904. 10.1096/fj.14666266668

667 Islam H, Edgett BA, Bonafiglia JT, Shulman T, Ma A, Quadrilatero J, Simpson CA, and Gurd 668 BJ. 2019. Repeatability of exercise-induced changes in mRNA expression and technical 669 considerations for qPCR analysis in human skeletal muscle. Exp Physiol 104:407-420. $670 \quad 10.1113 / \mathrm{EP} 087401$ 
671 Islam H, Edgett BA, and Gurd BJ. 2018. Coordination of mitochondrial biogenesis by PGC-

672 1alpha in human skeletal muscle: A re-evaluation. Metabolism 79:42-51.

673 10.1016/j.metabol.2017.11.001

674 Jamnick NA, Botella J, Pyne DB, and Bishop DJ. 2018. Manipulating graded exercise test

675 variables affects the validity of the lactate threshold and VO2peak. PLoS One 13:e0199794.

676 10.1371/journal.pone.0199794

677 Jamnick NA, Pettitt RW, Granata C, Pyne DB, and Bishop DJ. 2020. An Examination and

678 Critique of Current Methods to Determine Exercise Intensity. Sports Med. 10.1007/s40279-020-

$679 \quad 01322-8$

680 Jensen L, Gejl KD, Ortenblad N, Nielsen JL, Bech RD, Nygaard T, Sahlin K, and Frandsen U.

681 2015. Carbohydrate restricted recovery from long term endurance exercise does not affect gene

682 responses involved in mitochondrial biogenesis in highly trained athletes. Physiol Rep 3.

683 10.14814/phy2.12184

684 Kemler D, Wolff CA, and Esser KA. 2020. Time-of-day dependent effects of contractile activity 685 on the phase of the skeletal muscle clock. J Physiol 598:3631-3644. 10.1113/JP279779

686 Kuang J, Yan X, Genders AJ, Granata C, and Bishop DJ. 2018. An overview of technical 687 considerations when using quantitative real-time PCR analysis of gene expression in human 688 exercise research. PLoS One 13:e0196438. 10.1371/journal.pone.0196438

689 Kuipers H, Verstappen FT, Keizer HA, Geurten P, and van Kranenburg G. 1985. Variability of 690 aerobic performance in the laboratory and its physiologic correlates. International journal of 691 sports medicine 6:197-201. 10.1055/s-2008-1025839

692 Lavie CJ, Arena R, Swift DL, Johannsen NM, Sui X, Lee DC, Earnest CP, Church TS, O'Keefe $693 \mathrm{JH}$, Milani RV, and Blair SN. 2015. Exercise and the cardiovascular system: clinical science and 694 cardiovascular outcomes. Circ Res 117:207-219. 10.1161/CIRCRESAHA.117.305205

695 Li JJ, Bickel PJ, and Biggin MD. 2014. System wide analyses have underestimated protein 696 abundances and the importance of transcription in mammals. PeerJ 2:e270. 10.7717/peerj.270

697 Lindholm ME, Marabita F, Gomez-Cabrero D, Rundqvist H, Ekstrom TJ, Tegner J, and

698 Sundberg CJ. 2014. An integrative analysis reveals coordinated reprogramming of the 
699 epigenome and the transcriptome in human skeletal muscle after training. Epigenetics 9:1557-

700 1569. 10.4161/15592294.2014.982445

701 Liu D, Sartor MA, Nader GA, Gutmann L, Treutelaar MK, Pistilli EE, Iglayreger HB, Burant

702 CF, Hoffman EP, and Gordon PM. 2010. Skeletal muscle gene expression in response to

703 resistance exercise: sex specific regulation. BMC Genomics 11:659. 10.1186/1471-2164-11-659

704 Lundby C, Nordsborg N, Kusuhara K, Kristensen KM, Neufer PD, and Pilegaard H. 2005. Gene

705 expression in human skeletal muscle: alternative normalization method and effect of repeated

706 biopsies. Eur J Appl Physiol 95:351-360. 10.1007/s00421-005-0022-7

707 Mahoney DJ, Parise G, Melov S, Safdar A, and Tarnopolsky MA. 2005. Analysis of global

708 mRNA expression in human skeletal muscle during recovery from endurance exercise. FASEB $J$

709 19:1498-1500. 10.1096/fj.04-3149fje

710 Mathai AS, Bonen A, Benton CR, Robinson DL, and Graham TE. 2008. Rapid exercise-induced

711 changes in PGC-1alpha mRNA and protein in human skeletal muscle. J Appl Physiol 105:1098-

712 1105. 10.1152/japplphysiol.00847.2007

713 McGinley C, and Bishop DJ. 2016a. Distinct protein and mRNA kinetics of skeletal muscle

714 proton transporters following exercise can influence interpretation of adaptations to training. Exp

715 Physiol 101:1565-1580. 10.1113/ep085921

716 McGinley C, and Bishop DJ. 2016b. Influence of training intensity on adaptations in acid/base

717 transport proteins, muscle buffer capacity, and repeated-sprint ability in active men. $J$ Appl

718 Physiol 121:1290-1305. 10.1152/japplphysiol.00630.2016

719 McLean CS, Mielke C, Cordova JM, Langlais PR, Bowen B, Miranda D, Coletta DK, and

720 Mandarino LJ. 2015. Gene and MicroRNA Expression Responses to Exercise; Relationship with

721 Insulin Sensitivity. PLoS One 10:e0127089. 10.1371/journal.pone.0127089

722 Miyamoto-Mikami E, Tsuji K, Horii N, Hasegawa N, Fujie S, Homma T, Uchida M, Hamaoka

723 T, Kanehisa H, Tabata I, and Iemitsu M. 2018. Gene expression profile of muscle adaptation to

724 high-intensity intermittent exercise training in young men. Sci Rep 8:16811. 10.1038/s41598-

$725 \quad 018-35115-x$

726 Murton AJ, Billeter R, Stephens FB, Des Etages SG, Graber F, Hill RJ, Marimuthu K, and

727 Greenhaff PL. 2014. Transient transcriptional events in human skeletal muscle at the outset of

Peer] reviewing PDF | (2021:08:64564:2:0:NEW 15 Dec 2021) 
728 concentric resistance exercise training. J Appl Physiol 116:113-125.

729 10.1152/japplphysiol.00426.2013

730 Neubauer O, Sabapathy S, Ashton KJ, Desbrow B, Peake JM, Lazarus R, Wessner B, Cameron-

731 Smith D, Wagner KH, Haseler LJ, and Bulmer AC. 2014. Time course-dependent changes in the

732 transcriptome of human skeletal muscle during recovery from endurance exercise: from

733 inflammation to adaptive remodeling. J Appl Physiol 116:274-287.

734 10.1152/japplphysiol.00909.2013

735 Newell J, Higgins D, Madden N, Cruickshank J, Einbeck J, McMillan K, and McDonald R. 736 2007. Software for calculating blood lactate endurance markers. Journal of Sports Sciences 737 25:1403-1409. Doi 10.1080/02640410601128922

738 Ogborn DI, McKay BR, Crane JD, Safdar A, Akhtar M, Parise G, and Tarnopolsky MA. 2015. 739 Effects of age and unaccustomed resistance exercise on mitochondrial transcript and protein 740 abundance in skeletal muscle of men. Am J Physiol Regul Integr Comp Physiol 308:R734-741.

741 10.1152/ajpregu.00005.2014

742 Perry CG, Lally J, Holloway GP, Heigenhauser GJ, Bonen A, and Spriet LL. 2010. Repeated 743 transient mRNA bursts precede increases in transcriptional and mitochondrial proteins during 744 training in human skeletal muscle. J Physiol 588:4795-4810. 10.1113/jphysiol.2010.199448

745 Philippou A, Chryssanthopoulos C, Maridaki M, Dimitriadis G, and Koutsilieris M. 2019.

746 Exercise Metabolism in Health and Disease. In: Kokkinos P, and Narayan P, eds.

747 Cardiorespiratory Fitness in Cardiometabolic Diseases: Prevention and Management in

748 Clinical Practice. Cham: Springer International Publishing, 57-96. 10.1007/978-3-030-04816749 7_5

750 Pilegaard H, Saltin B, and Neufer PD. 2003. Exercise induces transient transcriptional activation 751 of the PGC-1alpha gene in human skeletal muscle. J Physiol 546:851-858.

752 10.1113/jphysiol.2002.034850

753 Pillon NJ, Gabriel BM, Dollet L, Smith JAB, Sardon Puig L, Botella J, Bishop DJ, Krook A, and 754 Zierath JR. 2020. Transcriptomic profiling of skeletal muscle adaptations to exercise and 755 inactivity. Nat Commun 11:470. 10.1038/s41467-019-13869-w 
756 Popov DV, Lysenko EA, Bokov RO, Volodina MA, Kurochkina NS, Makhnovskii PA,

757 Vyssokikh MY, and Vinogradova OL. 2018. Effect of aerobic training on baseline expression of

758 signaling and respiratory proteins in human skeletal muscle. Physiol Rep 6:e13868.

$759 \quad 10.14814 /$ phy 2.13868

760 Popov DV, Lysenko EA, Makhnovskii PA, Kurochkina NS, and Vinogradova OL. 2017.

761 Regulation of PPARGC1A gene expression in trained and untrained human skeletal muscle.

762 Physiol Rep 5. 10.14814/phy2.13543

763 Psilander N, Damsgaard R, and Pilegaard H. 2003. Resistance exercise alters MRF and IGF-I

764 mRNA content in human skeletal muscle. J Appl Physiol 95:1038-1044.

765 10.1152/japplphysiol.00903.2002

766 Raue U, Trappe TA, Estrem ST, Qian HR, Helvering LM, Smith RC, and Trappe S. 2012.

767 Transcriptome signature of resistance exercise adaptations: mixed muscle and fiber type specific

768 profiles in young and old adults. J Appl Physiol 112:1625-1636.

769 10.1152/japplphysiol.00435.2011

770 Ross R, de Lannoy L, and Stotz PJ. 2015. Separate Effects of Intensity and Amount of Exercise

771 on Interindividual Cardiorespiratory Fitness Response. Mayo Clin Proc 90:1506-1514.

772 10.1016/j.mayocp.2015.07.024

773 Ross R, Goodpaster BH, Koch LG, Sarzynski MA, Kohrt WM, Johannsen NM, Skinner JS, 774 Castro A, Irving BA, Noland RC, Sparks LM, Spielmann G, Day AG, Pitsch W, Hopkins WG, 775 and Bouchard C. 2019. Precision exercise medicine: understanding exercise response variability.

776 Br J Sports Med. 10.1136/bjsports-2018-100328

777 Rowlands DS, Thomson JS, Timmons BW, Raymond F, Fuerholz A, Mansourian R, Zwahlen

778 MC, Métairon S, Glover E, Stellingwerff T, Kussmann M, and Tarnopolsky MA. 2011.

779 Transcriptome and translational signaling following endurance exercise in trained skeletal

780 muscle: impact of dietary protein. Physiol Genomics 43:1004-1020.

781 10.1152/physiolgenomics.00073.2011

782 Saleem A, Carter HN, Iqbal S, and Hood DA. 2011. Role of p53 within the regulatory network 783 controlling muscle mitochondrial biogenesis. Exerc Sport Sci Rev 39:199-205.

784 10.1097/JES.0b013e31822d71be 
785 Saleem A, and Hood DA. 2013. Acute exercise induces tumour suppressor protein p53

786 translocation to the mitochondria and promotes a p53-Tfam-mitochondrial DNA complex in

787 skeletal muscle. J Physiol 591:3625-3636. 10.1113/jphysiol.2013.252791

788 Saner NJ, Lee MJ, Kuang J, Pitchford NW, Roach GD, Garnham A, Genders AJ, Stokes T,

789 Schroder EA, Huo Z, Esser KA, Phillips SM, Bishop DJ, and Bartlett JD. 2020. Exercise

790 mitigates sleep-loss-induced changes in glucose tolerance, mitochondrial function, sarcoplasmic

791 protein synthesis, and diurnal rhythms. Mol Metab:101110. 10.1016/j.molmet.2020.101110

792 Schmittgen TD, and Livak KJ. 2008. Analyzing real-time PCR data by the comparative $\mathrm{C}_{\mathrm{T}}$

793 method. Nat Protoc 3:1101-1108. 10.1038/nprot.2008.73

794 Scribbans TD, Edgett BA, Bonafiglia JT, Baechler BL, Quadrilatero J, and Gurd BJ. 2017. A

795 systematic upregulation of nuclear and mitochondrial genes is not present in the initial

796 postexercise recovery period in human skeletal muscle. Appl Physiol Nutr Metab 42:571-578.

797 10.1139/apnm-2016-0455

798 Sriwijitkamol A, Coletta DK, Wajcberg E, Balbontin GB, Reyna SM, Barrientes J, Eagan PA,

799 Jenkinson CP, Cersosimo E, DeFronzo RA, Sakamoto K, and Musi N. 2007. Effect of acute

800 exercise on AMPK signaling in skeletal muscle of subjects with type 2 diabetes: a time-course

801 and dose-response study. Diabetes 56:836-848. 10.2337/db06-1119

802 Stepto NK, Benziane B, Wadley GD, Chibalin AV, Canny BJ, Eynon N, and McConell GK.

803 2012. Short-term intensified cycle training alters acute and chronic responses of PGC1alpha and

804 Cytochrome C oxidase IV to exercise in human skeletal muscle. PLoS One 7:e53080.

805 10.1371/journal.pone.0053080

806 Stuart CA, Howell ME, Baker JD, Dykes RJ, Duffourc MM, Ramsey MW, and Stone MH. 2010.

807 Cycle training increased GLUT4 and activation of mammalian target of rapamycin in fast twitch

808 muscle fibers. Med Sci Sports Exerc 42:96-106. 10.1249/MSS.0b013e3181ad7f36

809 Thalacker-Mercer A, Stec M, Cui X, Cross J, Windham S, and Bamman M. 2013. Cluster

810 analysis reveals differential transcript profiles associated with resistance training-induced human

811 skeletal muscle hypertrophy. Physiol Genomics 45:499-507.

812 10.1152/physiolgenomics.00167.2012 
813 Uhlitz F, Sieber A, Wyler E, Fritsche-Guenther R, Meisig J, Landthaler M, Klinger B, and 814 Bluthgen N. 2017. An immediate-late gene expression module decodes ERK signal duration.

815 Mol Syst Biol 13:944. 10.15252/msb.20177986

816 Vandesompele J, De Preter K, Pattyn F, Poppe B, Van Roy N, De Paepe A, and Speleman F.

817 2002. Accurate normalization of real-time quantitative RT-PCR data by geometric averaging of

818 multiple internal control genes. Genome Biol 3:research0034.0031-0034.0011. 10.1186/gb-

819 2002-3-7-research0034

820 Vissing K, Andersen JL, and Schjerling P. 2005. Are exercise-induced genes induced by

821 exercise? FASEB J 19:94-96. 10.1096/fj.04-2084fje

822 Vissing K, and Schjerling P. 2014. Simplified data access on human skeletal muscle

823 transcriptome responses to differentiated exercise. Sci Data 1:140041. 10.1038/sdata.2014.41

824 Xiao Y, Hsiao TH, Suresh U, Chen HI, Wu X, Wolf SE, and Chen Y. 2014. A novel significance 825 score for gene selection and ranking. Bioinformatics 30:801-807. 10.1093/bioinformatics/btr671

826 Xie F, Xiao P, Chen D, Xu L, and Zhang B. 2012. miRDeepFinder: a miRNA analysis tool for 827 deep sequencing of plant small RNAs. Plant Mol Biol. 10.1007/s11103-012-9885-2

828 Yang E, van Nimwegen E, Zavolan M, Rajewsky N, Schroeder M, Magnasco M, and Darnell JE, 829 Jr. 2003. Decay rates of human mRNAs: correlation with functional characteristics and sequence 830 attributes. Genome Res 13:1863-1872. 10.1101/gr.1272403

831 Yang Y, Creer A, Jemiolo B, and Trappe S. 2005. Time course of myogenic and metabolic gene 832 expression in response to acute exercise in human skeletal muscle. J Appl Physiol 98:1745-1752. 833 10.1152/japplphysiol.01185.2004

834 Ye J, Coulouris G, Zaretskaya I, Cutcutache I, Rozen S, and Madden TL. 2012. Primer-BLAST: 835 a tool to design target-specific primers for polymerase chain reaction. BMC Bioinformatics 836 13:134. 10.1186/1471-2105-13-134 


\section{Table $\mathbf{1}$ (on next page)}

Primer sequences and amplicon details. 
1 Table 1 Primer sequences and amplicon details.

\begin{tabular}{|c|c|c|c|c|}
\hline Gene & $\begin{array}{l}\text { Accessio } \\
\text { n no. }\end{array}$ & $\begin{array}{l}\text { Primers (Forward and } \\
\text { Reverse) }\end{array}$ & $\begin{array}{l}\text { Amplicon } \\
\text { size (bp) }\end{array}$ & $\begin{array}{c}\text { Efficienc } \\
\text { y (\%) }\end{array}$ \\
\hline $\begin{array}{l}\text { TBP (TATA-box binding } \\
\text { protein) }\end{array}$ & $\begin{array}{l}\text { NM_00319 } \\
4.4\end{array}$ & $\begin{array}{l}\text { F: } \\
\text { CAGTGACCCAGCAGCAT } \\
\text { СACT } \\
\text { R: } \\
\text { AGGCCAAGCCCTGAGCG } \\
\text { TAA }\end{array}$ & 205 & 99 \\
\hline $\begin{array}{l}\text { Cyclophilin (PPIA, peptidyl- } \\
\text { prolyl cis-trans isomerase } \\
\text { A) }\end{array}$ & $\begin{array}{l}\text { NM_02113 } \\
0.4\end{array}$ & $\begin{array}{l}\text { F: } \\
\text { GTCAACCCCACCGTGTTC } \\
\text { TTC } \\
\text { R: } \\
\text { TTTCTGCTGTCTTTGGGA } \\
\text { CCTTG }\end{array}$ & 100 & 100 \\
\hline B2M ( $\beta$-2-microglobulin) & $\begin{array}{l}\text { NM_00404 } \\
8.2\end{array}$ & $\begin{array}{l}\text { F: } \\
\text { TGCTGTCTCCATGTTTGA } \\
\text { TGTATCT } \\
\text { R: } \\
\text { TCTCTGCTCCCCACCTCT } \\
\text { AAGT }\end{array}$ & 86 & 98 \\
\hline ACTB (actin beta) & $\begin{array}{l}\text { NM_00110 } \\
1.3\end{array}$ & $\begin{array}{l}\text { F:GAGCACAGAGCCTCGC } \\
\text { CTTT } \\
\text { R:TCATCATCCATGGTGA } \\
\text { GCTGGC }\end{array}$ & 70 & 107 \\
\hline $\begin{array}{l}\text { 18S rRNA (RNA, 18S } \\
\text { ribosomal 5) }\end{array}$ & $\begin{array}{l}\text { NR_00328 } \\
6.2\end{array}$ & $\begin{array}{l}\text { F:CTTAGAGGGACAAGTG } \\
\text { GCG }\end{array}$ & 71 & 99 \\
\hline
\end{tabular}


R:GGACATCTAAGGGCAT

CACA

GAPDH (glyceraldehyde-3- NM_00128 F:AATCCCATCACCATCTT

82

106

phosphate dehydrogenase) $\quad 9746.1 \quad$ CCA

R:TGGACTCCACGACGTA

CTCA

PGC-1a (peroxisome

NM_01326 F:CAGCCTCTTTGCCCAG

101

104

proliferator-activated

1.3

ATCTT

receptor gamma

R:TCACTGCACCACTTGA

coactivator $1 \alpha$,

GTCCAC

PPARGC1A)

PGC-1a, isoform 4

Adapted F:TCACACCAAACCCACA

$\mathrm{n} / \mathrm{a}$

114

from (Ruas GAGA

et al. 2012) R:CTGGAAGATATGGCAC

AT

PPARa (peroxisome

NM_00133 F:GGCAGAAGAGCCGTCT

102

93

proliferator activated

0751.1

CTACTTA

receptor $\alpha)$

R:TTTGCATGGTTCTGGGT

ACTGA

HSPA1A (heat shock

NM_00534

F:GGGCCTTTCCAAGATT

95

99

protein family A member

1A)

$5.5 \quad$ GCTG

R:TGCAAACACAGGAAATT

GAGAACT

SDHB (succinate

NM_00300 F:

102

104

dehydrogenase complex

0.2

AAATGTGGCCCCATGGTA

iron sulfur subunit $B$ )

TTG

$\mathrm{R}$ :

AGAGCCACAGATGCCTTC 
TCTG

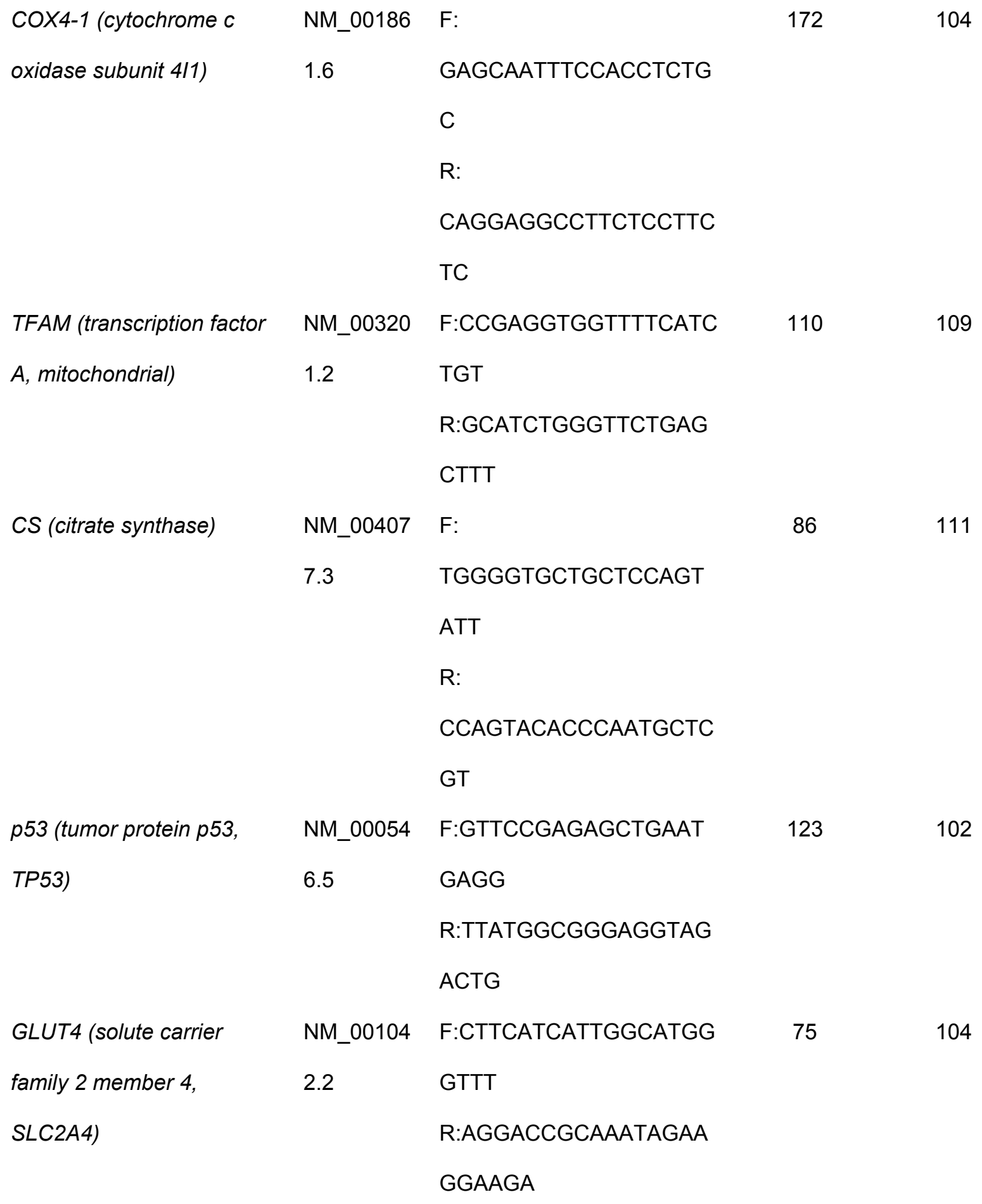




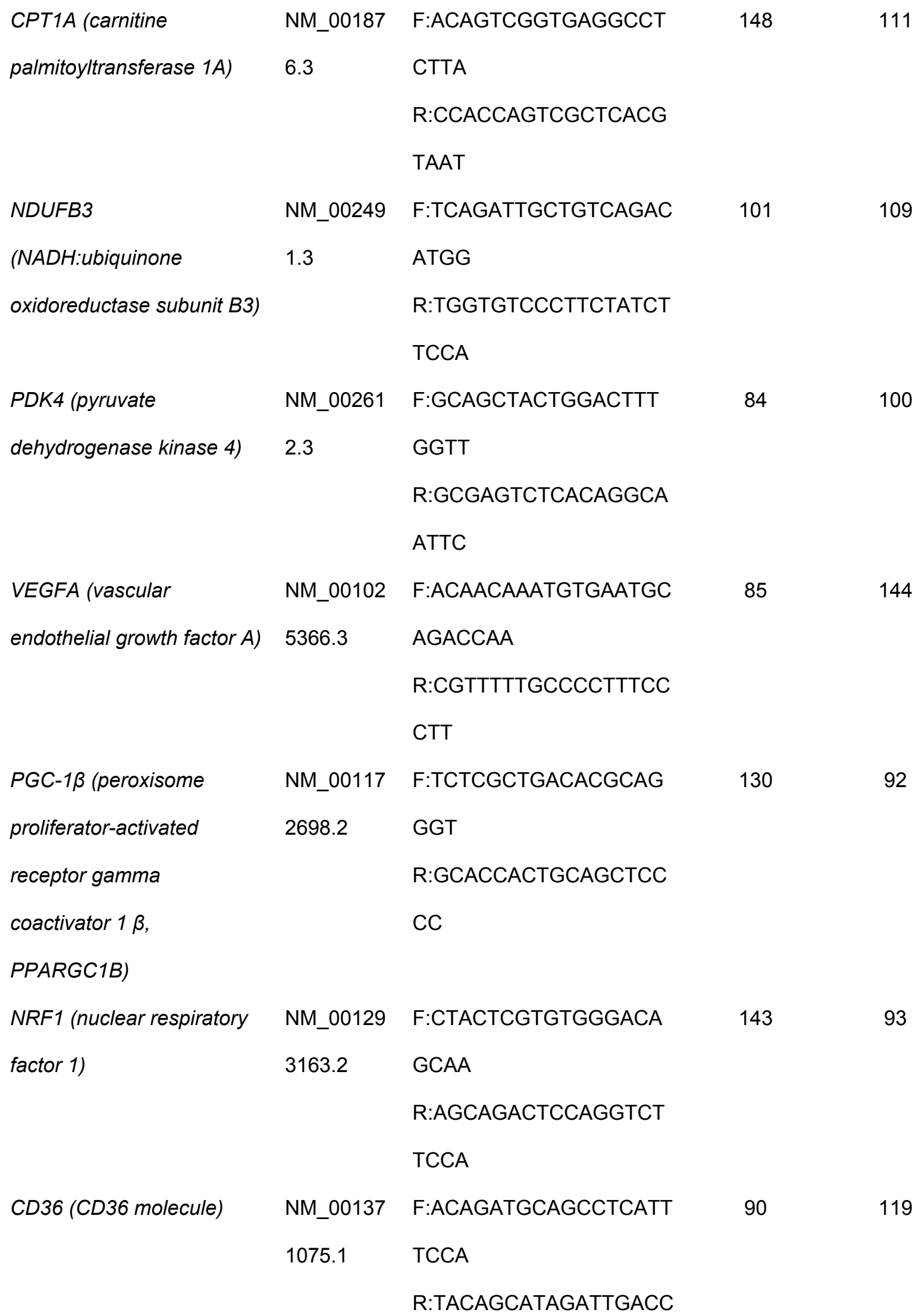


TGCAA

\begin{tabular}{|c|c|c|c|c|}
\hline TFEB (transcription factor & NM_00716 & F:CAGATGCCCAACACGC & 140 & 102 \\
\hline$E B)$ & 2.2 & $\begin{array}{l}\text { TACC } \\
\text { R:GCATCTGTGAGCTCTC } \\
\text { GCTT }\end{array}$ & & \\
\hline $\begin{array}{l}\text { UCP3 (uncoupling protein } \\
\text { 3) }\end{array}$ & $\begin{array}{l}\text { NM_00335 } \\
6.4\end{array}$ & $\begin{array}{l}\text { F:CCACAGCCTTCTACAAG } \\
\text { GGATTTA } \\
\text { R:ACGAACATCACCACGT } \\
\text { TCCA }\end{array}$ & 70 & 90 \\
\hline $\begin{array}{l}\text { UQCRC2 (ubiquinol- } \\
\text { cytochrome c reductase } \\
\text { core protein 2) }\end{array}$ & $\begin{array}{l}\text { NM_00336 } \\
6.4\end{array}$ & $\begin{array}{l}\text { F:GCAGTGACCGTGTGTC } \\
\text { AGAA } \\
\text { R:AGGGAATAAAATCTCG } \\
\text { AGAAAGAGC }\end{array}$ & 79 & 100 \\
\hline $\begin{array}{l}P P A R \beta / \delta \text { (peroxisome } \\
\text { proliferator activated } \\
\text { receptor } \beta / \delta \text { ) }\end{array}$ & $\begin{array}{l}\text { NM_00623 } \\
8.4\end{array}$ & $\begin{array}{l}\text { F:CATCATTCTGTGTGGAG } \\
\text { ACCG } \\
\text { R:AGAGGTACTGGGCATC } \\
\text { AGGG }\end{array}$ & 125 & 109 \\
\hline $\begin{array}{l}\text { PPARY (peroxisome } \\
\text { proliferator activated } \\
\text { receptor } y \text { ) }\end{array}$ & $\begin{array}{l}\text { NM_13871 } \\
2.3\end{array}$ & $\begin{array}{l}\text { F:CTTGTGAAGGATGCAA } \\
\text { GGGTT } \\
\text { R:GAGACATCCCCACTGC } \\
\text { AAGG }\end{array}$ & 150 & 104 \\
\hline MFN2 (mitofusin 2) & $\begin{array}{l}\text { NM_01487 } \\
4.4\end{array}$ & $\begin{array}{l}\text { F:CCCCCTTGTCTTTATGC } \\
\text { TGATGTT } \\
\text { R:TTTTGGGAGAGGTGTT } \\
\text { GCTTATTTC }\end{array}$ & 168 & 134 \\
\hline
\end{tabular}




\section{Table 2 (on next page)}

Summary of changes in mRNA content following a single session of High-Intensity Interval Exercise (HIIE), measured in 9 participants.

The time-point with maximal fold changes, the geometric mean for maximal fold change with geometric standard deviation (GSD), the $95 \%$ Confidence Interval (Cl), the $p$ value determined by the Mann-Whitney test, the Xiao value determined by a novel posteriori information fusion scheme (Deshmukh et al. 2021; Xiao et al. 2014), the $q$ value determined by a Benjamini-Hochberg false discovery rate (FDR) of $<5 \%$, and the adjusted $p$ value (Adj $p$ value) determined by one-way ANOVA with Dunnett test, are reported for each target gene. 
1 Table 2 Summary of changes in mRNA content following a single session of High-Intensity 2 Interval Exercise (HIIE), measured in 9 participants. The time-point with maximal fold 3 changes, the geometric mean for maximal fold change with geometric standard deviation 4 (GSD), the $95 \%$ Confidence Interval $(\mathrm{Cl})$, the $p$ value determined by the Mann-Whitney 5 test, the Xiao value determined by a novel posteriori information fusion scheme (Deshmukh 6 et al. 2021; Xiao et al. 2014), the $q$ value determined by a Benjamini-Hochberg false 7 discovery rate (FDR) of $<5 \%$, and the adjusted $p$ value (Adj $p$ value) determined by one8 way ANOVA with Dunnett test, are reported for each target gene.

\begin{tabular}{|c|c|c|c|c|c|c|c|}
\hline $\begin{array}{l}\text { Gene } \\
\text { name }\end{array}$ & $\begin{array}{l}\text { Time-point } \\
\text { with } \\
\text { highest or } \\
\text { lowest fold } \\
\text { change }\end{array}$ & $\begin{array}{c}\text { Maximal fold } \\
\text { change relative to } \\
\text { baseline; } \\
\text { Geometric mean } \\
\text { (GSD) }\end{array}$ & $\begin{array}{l}95 \% \mathrm{Cl} \\
\text { for fold } \\
\text { change }\end{array}$ & $p$ value & $\begin{array}{l}\text { Xiao } \\
\text { value }\end{array}$ & $\begin{array}{c}q \\
\text { value }\end{array}$ & $\begin{array}{l}\text { Adj } p \\
\text { value }\end{array}$ \\
\hline$P G C-1 \alpha$ & $3 \mathrm{~h}$ & $3.2(1.8)$ & $2.0-5.0$ & 0.0005 & $\begin{array}{c}3.04 \times 10^{-} \\
6\end{array}$ & 0.0110 & 0.0052 \\
\hline $\begin{array}{l}P G C- \\
1 \alpha 4\end{array}$ & $3 \mathrm{~h}$ & $4.5(2.3)$ & $2.3-8.5$ & 0.0005 & $\begin{array}{c}7.35 \times 10^{-} \\
8\end{array}$ & 0.0110 & 0.0312 \\
\hline PPARa & $3 \mathrm{~h}$ & $4.1(1.5)$ & $3.0-5.6$ & 0.0003 & $\begin{array}{c}3.88 \times 10^{-} \\
7\end{array}$ & 0.0110 & 0.0251 \\
\hline CPT1A & $3 \mathrm{~h}$ & $2.9(2.8)$ & $1.3-6.3$ & 0.0503 & 0.0108 & 0.1614 & 0.0159 \\
\hline PDK4 & $9 \mathrm{~h}$ & $7.4(14)$ & $\begin{array}{l}1.0- \\
56.2\end{array}$ & 0.0315 & 0.0002 & 0.1242 & 0.1944 \\
\hline NRF1 & $24 \mathrm{~h}$ & $2.5(1.5)$ & $1.8-3.3$ & $<0.0001$ & $\begin{array}{c}5.66 \times 10^{-} \\
6\end{array}$ & 0.0069 & 0.0072 \\
\hline$C D 36$ & $24 \mathrm{~h}$ & $0.1(2.4)$ & $0.2-0.4$ & 0.0106 & 0.0001 & 0.0563 & 0.1223 \\
\hline TFEB & $24 \mathrm{~h}$ & $0.6(1.5)$ & $0.4-0.8$ & 0.0167 & 0.0500 & 0.0768 & 0.0222 \\
\hline
\end{tabular}




$\begin{array}{llllllll}\text { UCP3 } & 24 \mathrm{~h} & 2.4(4.4) & 0.8-7.4 & 0.0400 & 0.0179 & 0.1380 & 0.3903 \\ \text { p53 } & 48 \mathrm{~h} & 2.3(1.5) & 1.4-3.8 & 0.0078 & 0.0394 & 0.0454 & 0.1058 \\ \text { PPARY } & 48 \mathrm{~h} & 1.8(2.6) & 0.7-1.7 & 0.0147 & 0.0409 & 0.0700 & 0.5395 \\ & & & & & & & \\ \text { GLUT4 } & 72 \mathrm{~h} & 0.3(3.7) & 0.1-1.0 & 0.0004 & & & \\ & & & & & 7 & 0.0110 & 0.0072\end{array}$


Figure 1

Experimental Design.

Abbreviations: BM, body mass; CHO, carbohydrate; PRO, protein; GXT, graded exercise test;

HIIE, high-intensity interval exercise; HIIT, high-intensity interval training; <!--[if

!msEquation]--> <!--[endif]-- ${ }_{L T}$, power at the first lactate threshold; and <!--[if

!msEquation]--> <!--[endif]--> ${ }_{\text {peak }}$ peak aerobic power.

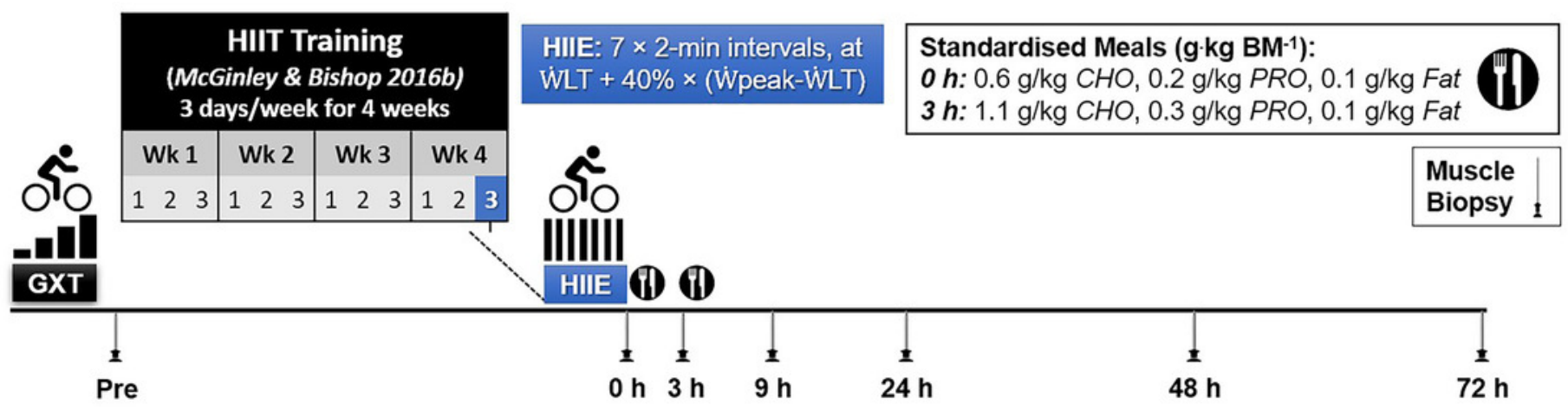




\section{Figure 2}

Relative fold changes compared to baseline for the mRNA content of PGC-1 $\alpha$ (a), PGC-1 4 (b), PPAR $\alpha$ (c), PDK4 (d), NRF1 (e), CD36 (f), p53 (g), and GLUT4 (h) , following a single session of HIIE.

Muscle biopsies were obtained at rest (baseline) before 4 weeks of High-Intensity Interval Training (HIIT), immediately after the final session of HIIE (0 h), and 3, 9, 24, 48, and $72 \mathrm{~h}$ after exercise from 9 participants (except for only 6 participants at $72 \mathrm{~h}$ ). Symbols (open circles and squares) of the same color indicate mRNA data from 1 participant; the geometric mean (horizontal bars) \pm the $95 \%$ confidence interval $(\mathrm{Cl})$ are plotted for each graph. The squares indicate the data point with highest or lowest mRNA content for each participant. A dotted line was used to indicate $Y=1$. * Significantly different from baseline, determined by a posteriori information fusion scheme and a Benjamini-Hochberg false discovery rate (FDR) of $<5 \% .{ }^{*}$ Significantly different from baseline, determined by a posteriori information fusion scheme only. 
A

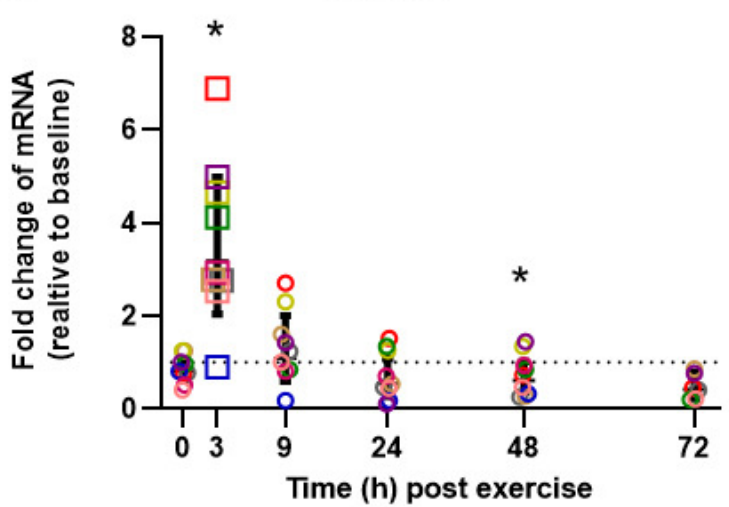

C

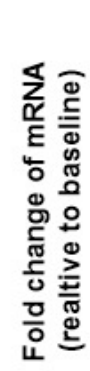

E
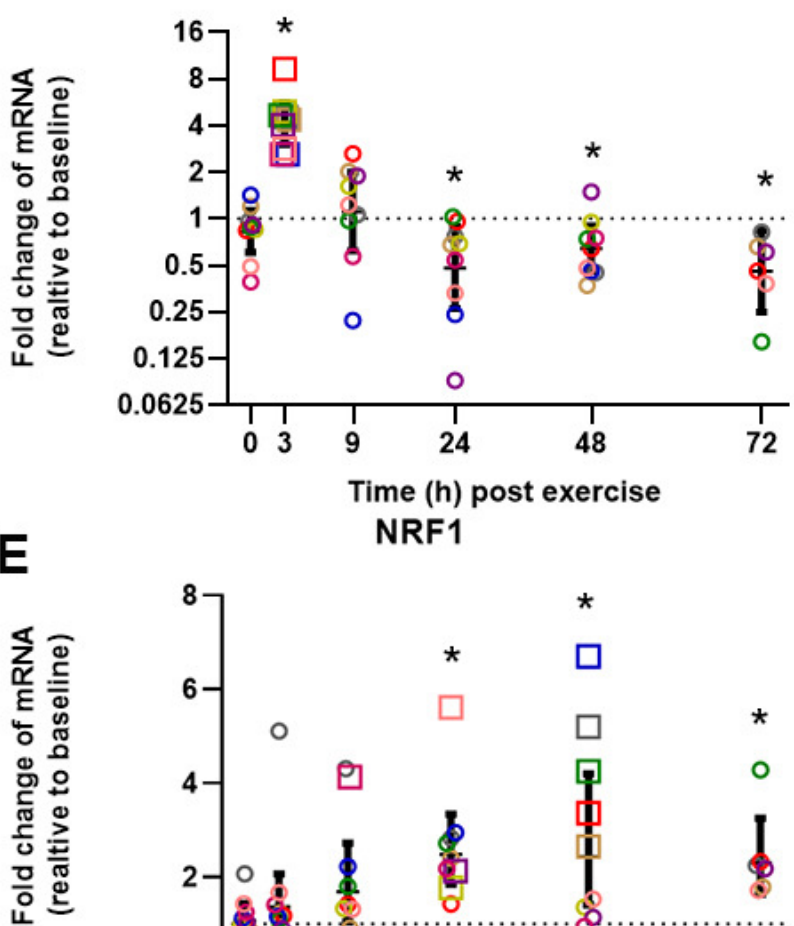

NRF1

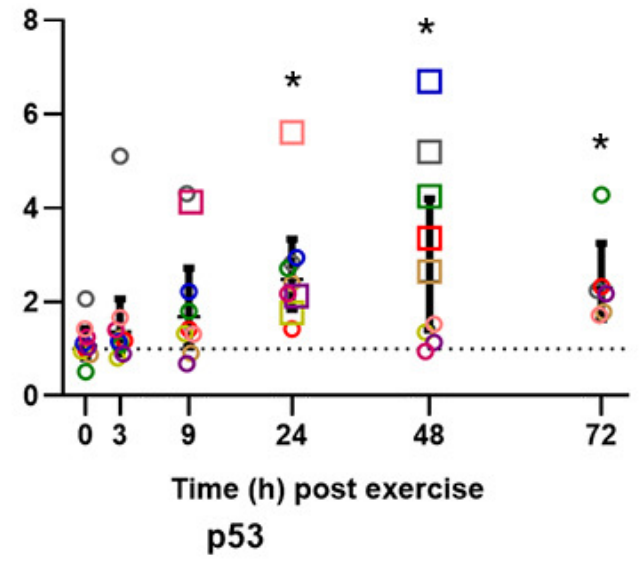

G

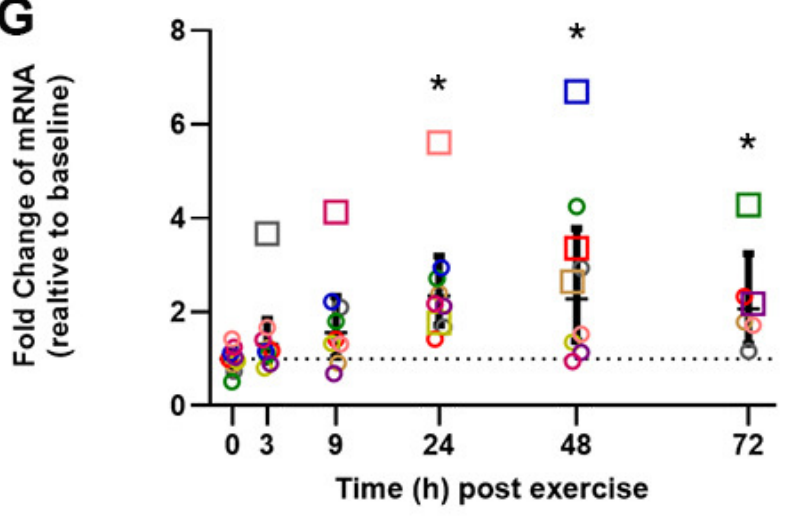

B

PGC-1 $\alpha 4$

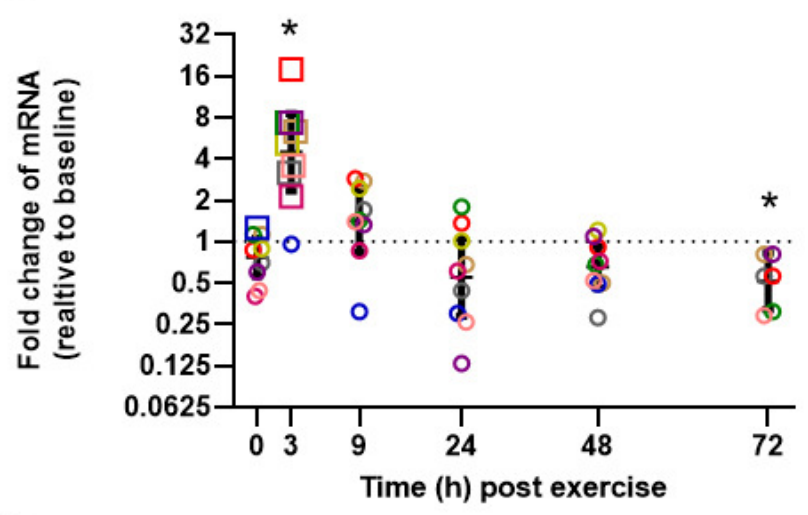

D

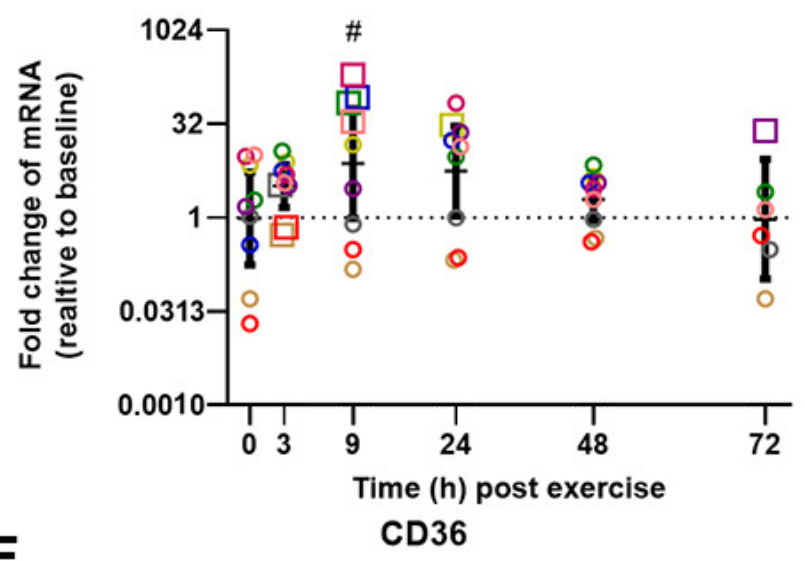

F

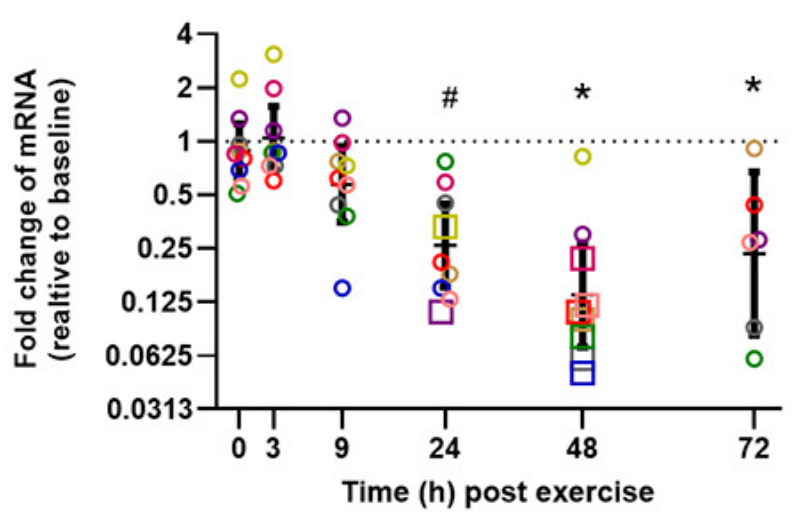

$\mathrm{H}$

GLUT4

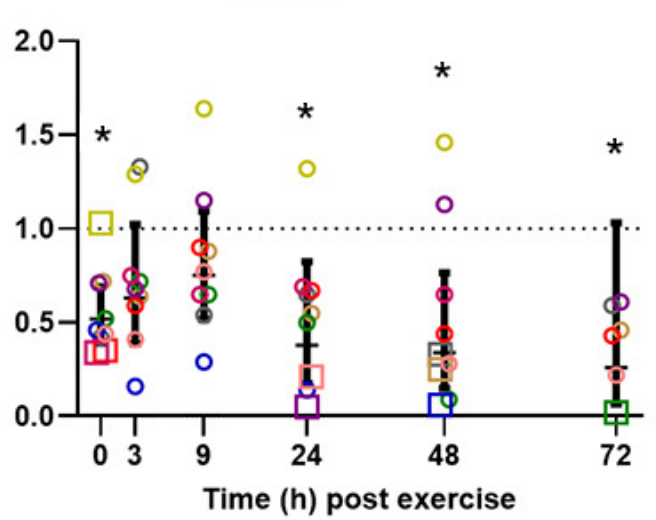




\section{Figure 3}

Curve fitting applied to mRNA changes following a single session of high-intensity interval exercise (HIIE).

Least-squares Gaussian nonlinear regression analysis (dash lines) has been applied to gene expression data for PGC-1 $\alpha$ (a), PGC-1 44 (b), PPAR $\alpha$ (c), PDK4 (d), NRF1 (e), CD36 (f), p53 (g), and GLUT4 (h) at 5 time-points (0, 3, 9, 24 and $48 \mathrm{~h}$ following a single session of HIIE) in 9 participants. The geometric mean of gene expression is indicated by black dots, error bars are geometric standard deviations. 
A

PGC-1 $\alpha$

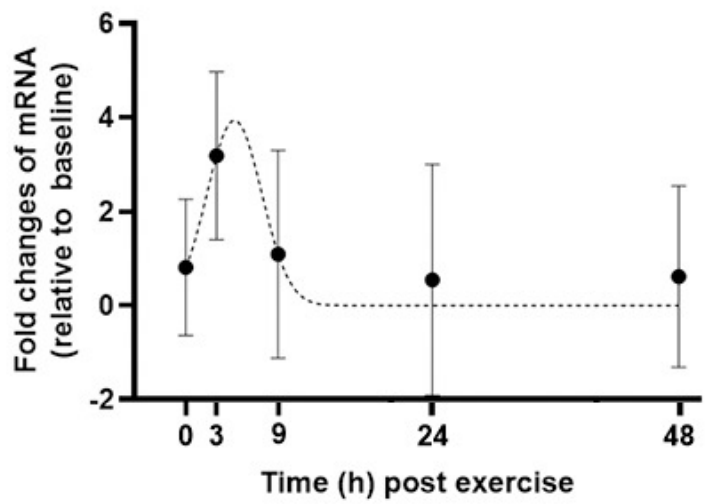

C

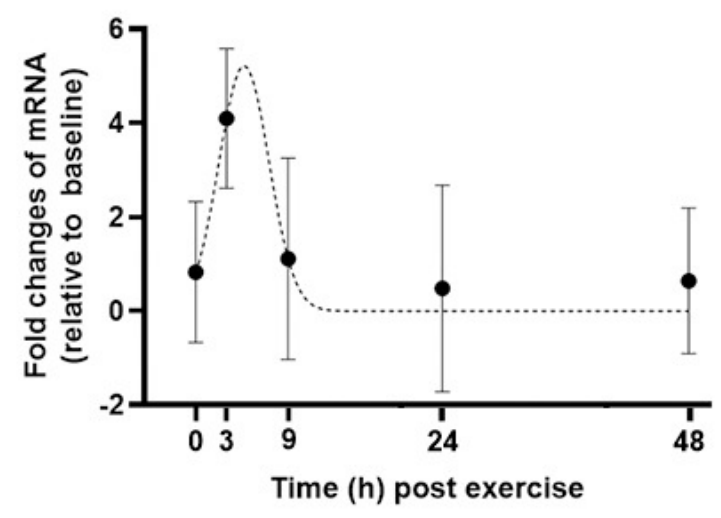

E

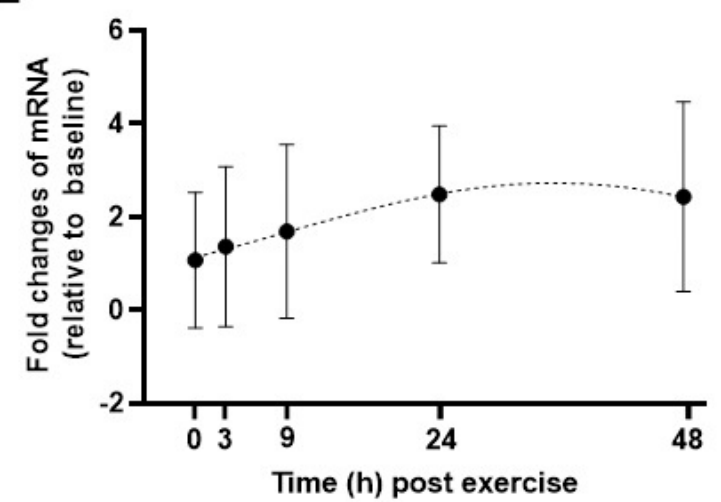

p53

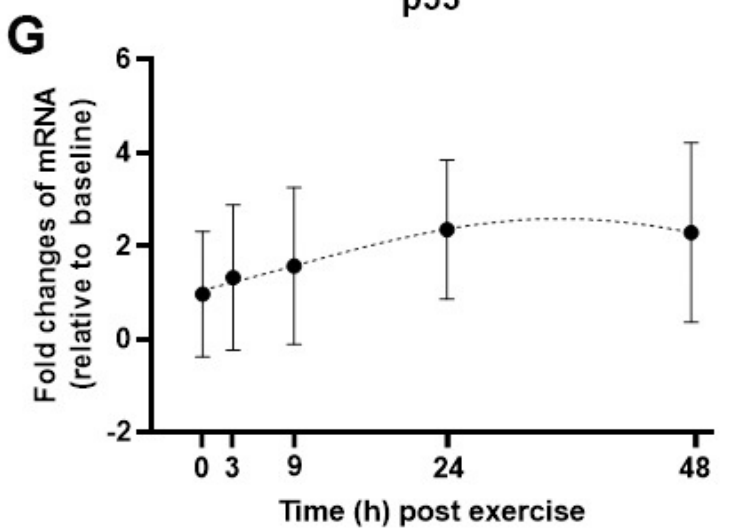

B

PGC-1a4

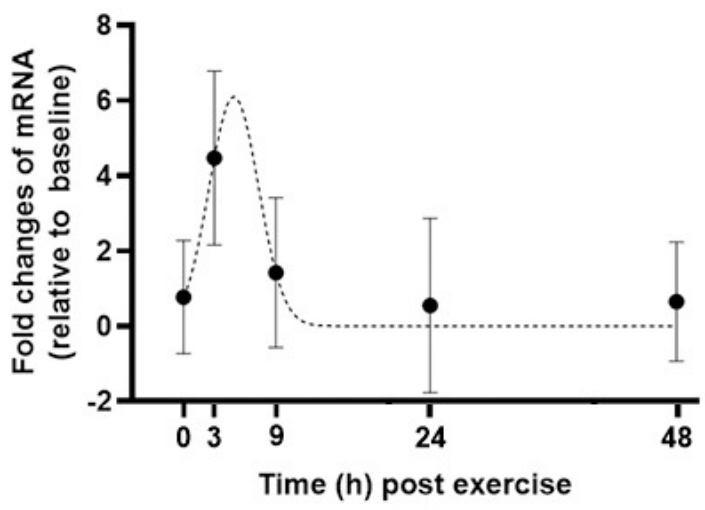

D
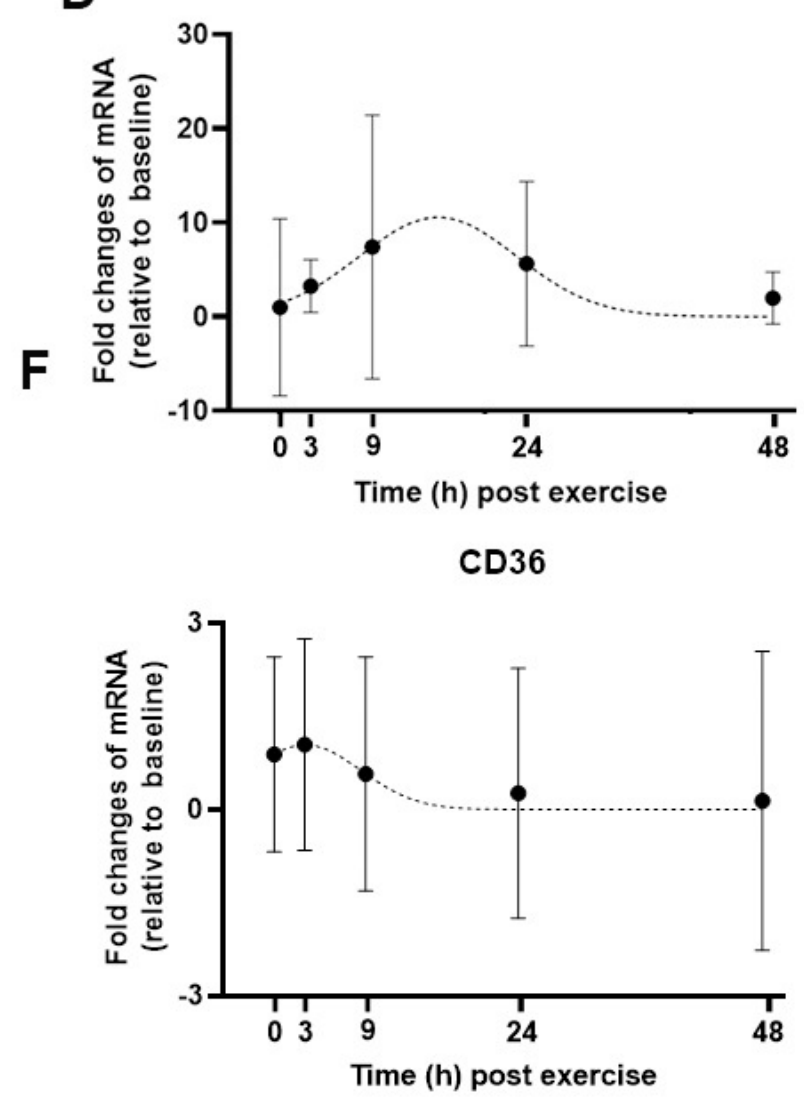

H

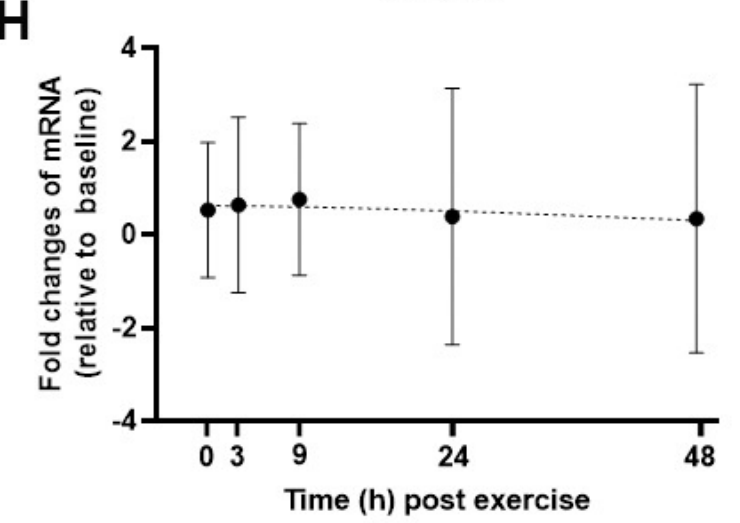


Figure 4

Modelled time of mRNA expression peak following a single session of high-intensity interval exercise in relation to biopsy timing in 9 participants.

The peak expression time (black dots) and the time window for the top $10 \%$ of mRNA content (vertical lines) were calculated based on regression analysis and is shown for the 7 genes (8 isoforms) for which a peak of gene expression was detected using curve fitting.

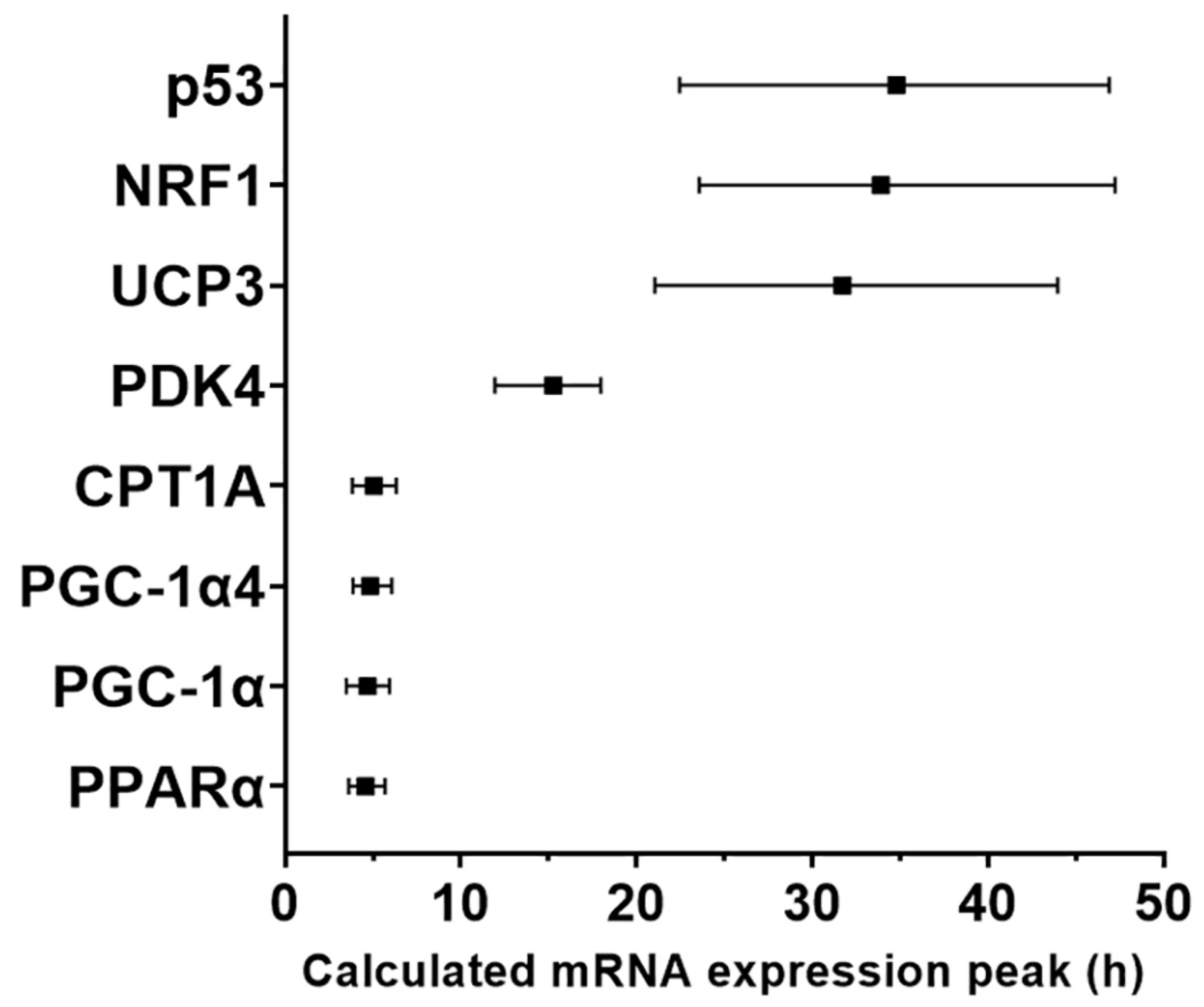


Figure 5

The biopsy time associated with peak mRNA expression in 9 participants plotted against the mRNA content at baseline for 12 gene isoforms.

Pearson's correlation coefficient and $p$ value are shown.

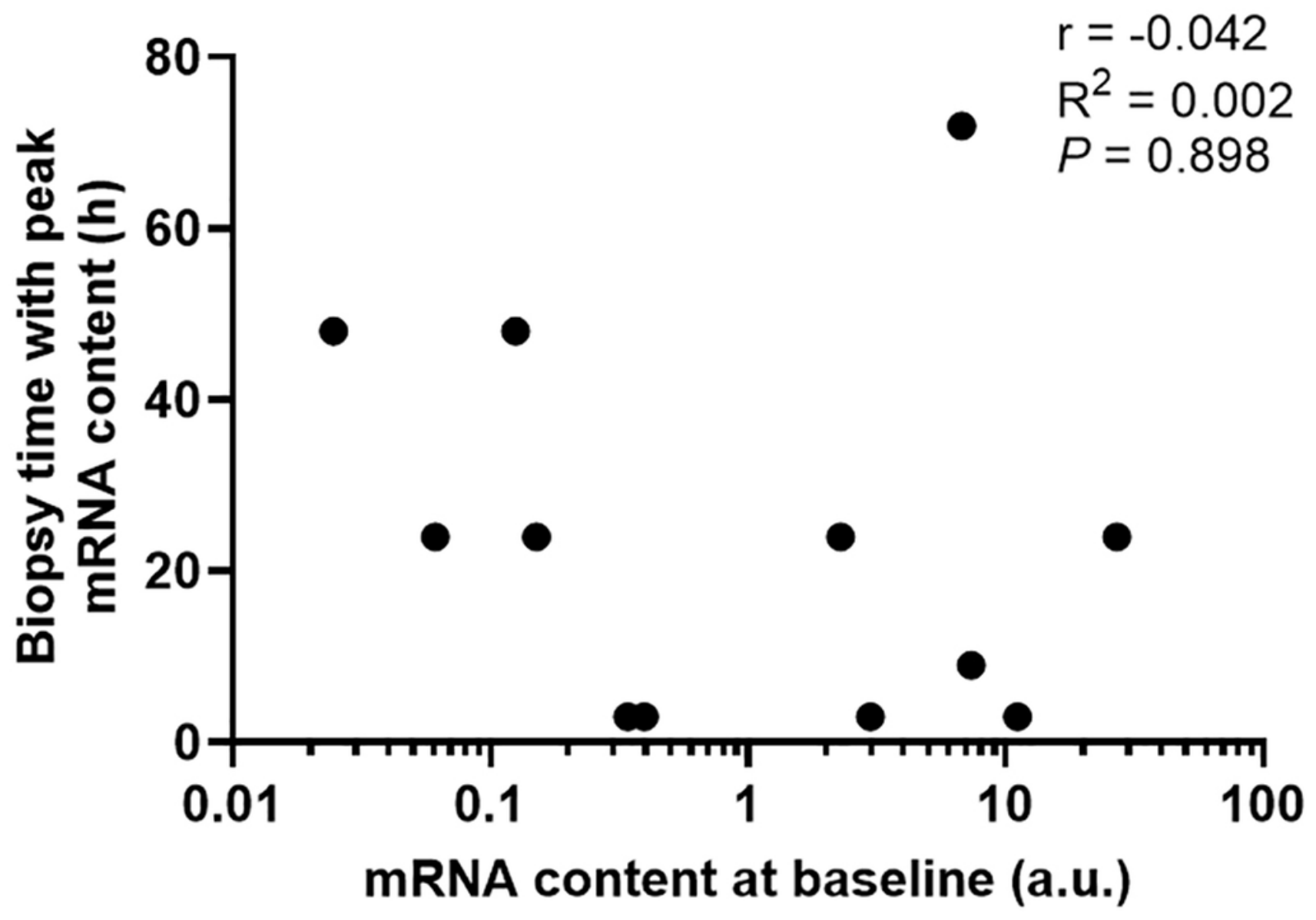

